Please cite as: . Lolli, A. Ishizaka, R. Gamberini, New AHP-based approaches for multi-criteria inventory classification, International Journal of Production Economics,

http://dx.doi.org/10.1016/j.ijpe.2014.05.015 (advance online publications)

\title{
New AHP-based approaches for Multi-Criteria Inventory Classification
}

\author{
F. Lolli ${ }^{\mathrm{a}}$, A. Ishizaka ${ }^{\mathrm{b}}$, R. Gamberini ${ }^{\mathrm{a}}$ \\ ${ }^{a}$ Department of Engineering Sciences and \\ Methods, University of Modena and Reggio \\ Emilia, Via Amendola 2 - Padiglione Morselli, \\ 42100 Reggio Emilia, Italy \\ Francesco.Lolli@unimore.it; Rita.Gamberini@unimore.it \\ ${ }^{\mathrm{b}}$ Portsmouth Business School, University of Portsmouth, \\ Portland Street - Richmond \\ Building, \\ Portsmouth PO1 3DE, UK \\ Alessio.Ishizaka@port.ac.uk
}

\begin{abstract}
Multi-Criteria Inventory Classification (MCIC) groups inventory items with respect to several criteria, in order to facilitate their management. This paper introduces a new hybrid method based on AHP and the K-means algorithm. On benchmarking data, it provides a clearly higher clustering validity index than previous sorting methods. However, as with previous methods, it is a full compensatory method. This means that an item scoring badly on one or more key criteria may still be placed in the best class because these bad scores are compensated. In order to prevent these hidden bad scores, a new variant method is introduced: AHP-K-Veto. The sorting is performed on each single criterion, where a veto system prevents an item evaluated as high/bad on at least one criterion to be top/bottom ranked in the global aggregation. This veto system is an assurance against hidden problems but slightly worsens the clustering validity index.
\end{abstract}

Keywords: Multiple criteria analysis, Assignment, Inventory, AHP, K-Means

\section{Introduction}

Inventory management may lead to significant savings (Johnson and Montgomery, 1974; Nahmias, 1997; Ghiani et al., 2004; Manzini and Gamberini, 2008). However, when there are a large number of items, the associated administrative effort and unused economy of scale of transportation and storage handling, may exceed the aforementioned savings. One solution to facilitate the management of the inventory is to group similar items in order to 
Please cite as: . Lolli, A. Ishizaka, R. Gamberini, New AHP-based approaches for multi-criteria inventory classification, International Journal of Production Economics,

http://dx.doi.org/10.1016/j.ijpe.2014.05.015 (advance online publications)

have a single policy for the bundle instead of a different policy for each item. For instance, the same target service level, which is the probability of not incurring in a stock-out during a replenishment cycle, could be associated to all the items of the same cluster. The critical issue in this process is how clusters are built. This question has been explored in depth in the literature since the development of the ABC inventory classification by Dickie (1951).

Traditionally, the ABC inventory is based on a single criterion, which is generally the annual usage value given by the product of the annual demand and the average unit price. Nevertheless, a single classifying criterion cannot generally represent the whole criticality of an item. Therefore, Multi-Criteria Inventory Classification (MCIC) methods, which include several other criteria, e.g., unit cost, lead time and availability, have been proposed (Flores and Whybark, 1986; Chen et al., 2008). The criteria to adopt depend on the aim of the classification and normally not on the classification technique. Therefore, last decade has provided several papers on how to improve these classification techniques. In this paper, a new hybrid AHP method with the K-Means algorithm, referred to as AHP-K, is proposed. This method provides a less subjective and more precise MCIC. A veto system is subsequently introduced in AHP-K-Veto, which is available when judged necessary by the decision maker, to prevent an item evaluated as high/low on at least one criterion to be bottom/top ranked, when an aggregation is made on all criteria. In this paper, the second approach is used to solve a real case study. Then, the dataset of Reid (1987) is adopted as a benchmark for the comparison of the performance of the new methods against the previous ones.

The paper has been organised as follows: Section 2 briefly describes the notation used in the paper. In Section 3, the main contributions in the literature on ABC clustering are briefly reviewed. Section 4 presents the AHP-K and AHP-K-Veto methods for MCIC and Section 5 shows the application of the presented methodologies through the real case study. Section 6 compares the proposed sorting approaches with the existing ones. Finally, Section 7 concludes the paper.

\section{Notation}

$I=$ total number of criteria;

$J=$ total number of items;

$N=$ number of classes;

$i=$ criterion, with $i=1, \ldots, I$; 
Please cite as: . Lolli, A. Ishizaka, R. Gamberini, New AHP-based approaches for multi-criteria inventory classification, International Journal of Production Economics,

http://dx.doi.org/10.1016/j.ijpe.2014.05.015 (advance online publications)

$a_{j}=$ item, with $j=1, \ldots, J$;

$v_{i, j}=$ value of item $a_{j}$ on the criterion $i$, with $i=1, \ldots, I$ and $j=1, \ldots, J$;

$w_{i, j}=$ weight on the criterion $i$ for the item $a_{j}$;

$C_{n, i}=$ class $n$ on criterion $i$, with $i=1, \ldots, I$ and $n=1, \ldots, N$;

$C_{n}=$ class $n$ on the final score, with $n=1, \ldots, N$.

\section{Literature review}

The literature on MCIC is extensive. As the benchmarking in our paper is based on the dataset provided by Reid (1987), we have mainly concentrated our review on the published papers that used this dataset. The last section presents some other approaches from artificial intelligence and explains why they are not suitable for our case.

\subsection{ABC clustering approach}

A pioneering approach in inventory classification is the $\mathrm{ABC}$ analysis on a single criterion, which is one of the most widely used techniques in organisations. According to this approach, resources spent on inventory control should be related to the importance of each item. Therefore, class A contains few items but constitutes the largest amount of annual usage value, whilst class $\mathrm{C}$ holds a large number of items but forms a small amount of annual usage value. Items that fall in between these two classes are assigned to class B. Several authors recognise that the traditional $\mathrm{ABC}$ analysis on a single criterion does not provide a satisfactory classification of inventory items (Guvenir and Erel, 1998; Huiskonen, 2001; Partovi and Anandarajan, 2002). Therefore, alternative MCICs are applied to take into account the multi-criteria structure of the problem and Flores and Whybark $(1986 ; 1987)$ proposed the first step in this direction. They developed a joint criteria matrix with two criteria: capital usage and lead time, in order to enrich the ABC grouping approach. However, the methodology becomes difficult to implement, as more criteria have to be considered. Ernst and Cohen (1986) suggested using a multi-criteria classification named Operations Related Groups (ORG) and stock control policies and then demonstrated through different case studies (Cohen and Ernst, 1988; Ernst and Cohen, 1990) that the ORG outperforms the $\mathrm{ABC}$ method in terms of both operational and statistical performance. After these contributions, MCIC has mainly been focused on three other approaches: AHP, DEA (Data Envelopment Analysis) and AI (Artificial Intelligence), which are reviewed in sections 3.2, 3.3 and 3.4 . 
Please cite as: . Lolli, A. Ishizaka, R. Gamberini, New AHP-based approaches for multi-criteria inventory classification, International Journal of Production Economics,

http://dx.doi.org/10.1016/j.ijpe.2014.05.015 (advance online publications)

\subsection{AHP-based approaches}

Flores et al. (1992) apply an AHP-based approach (see Saaty, 1980) that synthesises several weighted criteria (e.g., average unit cost, annual capital usage, criticality and lead time) into a single priority score for each item. AHP is a general-purpose method that can solve a broad range of multi-criteria problems. In particular, MCIC is a specific issue that can be faced with the application of AHP, where the alternatives correspond to the inventory items.

AHP can solve problems with qualitative and quantitative evaluations. These evaluations are entered into a pairwise comparison matrix. The importance of the criteria and ranking of the alternatives are then derived with the eigenvalue method (see Saaty, 1980; Ishizaka and Labib, 2011). Because the value of the items on each criterion in MCIC are often precisely measureable (e.g., lead time, costs, durability), Flores et al. (1992) simply normalised them in order to be commensurable and combinable in a weighted global score. The pairwise comparisons are only adopted to evaluate the importance of criteria with the eigenvalue method. This study demonstrates that AHP is more exhaustive than the ABC approach in supporting the policy development process, because the overall picture is taken into consideration and not just one single criterion. Several modified versions of AHP are applied in MCIC (Partovi and Burton, 1993; Partovi and Hopton, 1994), including a more recent AHP fuzzy version proposed by Cakir and Canbolat (2008).

Despite the specifics of each proposed method, it can be noted that the final sorting step, i.e., the attribution of each item to a criticality class (A, B or C), follows an exogenous rule imposed by the decision maker. For example, Flores et al. (1992) impose that the top $10 \%$ of items are assigned to class $\mathrm{A}$, the next $20 \%$ to class $\mathrm{B}$ and the last $70 \%$ to class $\mathrm{C}$. The paradoxical consequence of this rule is that two items having exactly the same score could be assigned to two different classes to satisfy these proportions. This approach, translated into terms of inventory control, leads to the management of these two similar items in different ways. In other words, the proposed methods are strongly affected by the arbitrary nature of the decision maker in the attribution of the items to the critically classes, without providing any objective or justifiable rules for achieving the cardinalities of these classes. It can be noted that such an approach is not always coherent with the aim of defining clusters of items with similar characteristics. 
Please cite as: . Lolli, A. Ishizaka, R. Gamberini, New AHP-based approaches for multi-criteria inventory classification, International Journal of Production Economics,

http://dx.doi.org/10.1016/j.ijpe.2014.05.015 (advance online publications)

In order to remove this arbitrariness, AHP-K is introduced (see section 4.1), which integrates AHP with the K-Means algorithm in order to make the clustering more objective. Subsequently, AHP-K-Veto is presented, in order to retain the presence of the decision maker with the faculty of imposing a veto on the final result.

\subsection{Weighted linear optimisation approaches}

Inspired from the Data Envelopment Analysis (DEA), Ramanathan (2006) introduces a weighted linear model (see Equations 1, 2 and 3), which via a linear optimisation, choose weights that show each item $j$ under its best profile:

$$
\begin{array}{ll}
\max & f_{j}=\sum_{i=1}^{I} w_{i, j} v_{i, j} \\
\text { s.t. } & \sum_{i=1}^{I} w_{i, j} v_{m, j} \leq 1, m=1,2, \ldots, J \\
& w_{i, j} \geq 0, \quad i=1,2, \ldots, I
\end{array}
$$

This formula is very similar to a simple weighted sum (SWS). The difference is that the weights are auto-generated (i.e., endogenous) and variable, whilst in the SWS, they are attributed by the decision maker (i.e., exogenous) and fixed for all items. The advantage of this method is that we do not require any input from the decision maker. This approach may be useful for new items, where the information on weights importance is not yet available due to the lack of experience. Unlike AHP, it is not compensatory in the sense that bad scores may be totally ignored. In order to limit this problem, $\mathrm{Ng}$ (2007) asks the decision maker for an ordinal ranking of the weights. This information is added as a constraint in the linear optimisation model. Later, Hadi-Vencheh (2010) modifies the normalisation constraint on the weights (Eq.4). The squared sum of the weights is normalised, in order to increase the distance between them and decrease the likelihood that the weakness of an item is ignored.

$$
\sum_{i=1}^{I} w_{i}^{2}=1
$$

On the same problem, Zhou and Fan (2007) use Eq.1 to calculate the most favourable weights for each item and then minimise the objective function (Eq.1) in order to find the least favourable weights. Based on these weights, good and bad indexes of weights are created. Both indexes are then combined in a weighted sum, where the decision maker subjectively defines the weights of both indexes. Chen (2011) has criticised this approach because only two extreme cases are considered and each item has its own set of weights, 
Please cite as: . Lolli, A. Ishizaka, R. Gamberini, New AHP-based approaches for multi-criteria inventory classification, International Journal of Production Economics,

http://dx.doi.org/10.1016/j.ijpe.2014.05.015 (advance online publications)

which makes them less comparable. He also added that a particular criterion might be neglected by receiving a weight of zero, especially if the number of criteria increases.

Therefore, he proposed calculating the weights for all items and using them to evaluate the efficiency of other items; hence, the name peer-evaluation or cross-evaluation instead of selfevaluation. Then, a second objective is used to maximise the cross-efficiency of other items. This means that the cross-efficiency has the advantage of preventing unrealistic weights (i.e., all criteria weights are zero apart from one) because they are diluted due to peer-estimation. However, this model is very complex, especially for a high number of items, as a second model must be solved. Moreover, the inclusion or suppression of an item can alter the final cross-efficiency, as it is a mean of weights (Angulo-Meza and Lins, 2002).

All the aforementioned authors use the dataset provided in Reid (1987) to validate their weighted linear optimisation approaches, with the aim of overcoming the subjectivity related to AHP due to the exogenous weights given to criteria. These approaches maintain the subjectivity in establishing the cardinalities of the clusters, as in Flores et al. (1992).

\subsection{AI-based techniques}

Artificial Intelligence-based (AI) techniques are recently gaining popularity (Yu, 2011). Guvenir and Erel (1998) propose a Genetic Algorithm for Multi-criteria Inventory Classification (GAMIC) to establish by learning the weights of the criteria and the AB and $\mathrm{BC}$ cut-off points from pre-classified items. The fitness of a chromosome reflects its ability to classify the training set correctly. Once the criteria weights are obtained, a simple weighted sum of the scores is applied to rate the criticality of an item. Items with a greater criticality than the $\mathrm{AB}$ cut-off value are classified as $\mathrm{A}$, those with values between $\mathrm{AB}$ and $\mathrm{BC}$ belong to class $\mathrm{B}$ and the remaining items are assigned to class $\mathrm{C}$.

Partovi and Anandarajan (2002) apply artificial neural networks (ANNs) for ABC classification of items. In particular, they use the backpropagation optimisation algorithm alone and then combined with genetic algorithms for the network parameters (learning rate, hidden units, input selection, and memory depth). The results obtained are compared with the multiple discriminate analysis (MDA) technique. ANNs outperform MDA in the accuracy of the prediction.

Analogously, Yu (2011) compares support vector machines (SVMs), backpropagation networks (BPNs), the k-nearest neighbour (k-NN) algorithm and multiple discriminate 
Please cite as: . Lolli, A. Ishizaka, R. Gamberini, New AHP-based approaches for multi-criteria inventory classification, International Journal of Production Economics,

http://dx.doi.org/10.1016/j.ijpe.2014.05.015 (advance online publications)

analysis (MDA). AI-based techniques demonstrate a superior accuracy. In particular, the SVMs approach was the most accurate.

Nevertheless, these methods have the disadvantage of requiring a learning set of preclassified items, which is not always available. In the dataset of Reid (1987), a learning set is not available. Therefore, Mohammaditabar et al. (2012) developed an optimisation model to minimise two objective functions: the total cost and the dissimilarity of items categorised in the same group. A simulated annealing was programmed and the database of Reid (1987) used as a benchmark. To be comparable with previous studies, the qualitative criteria must be integrated into the cost function to minimise, which leads to several cost assumptions.

\section{New AHP-based approaches}

\subsection{Introduction}

AHP has been introduced for ranking problems on qualitative and quantitative criteria (Saaty, 1980). It evaluates pairwise criteria with regard to the goal of the problem and also the alternatives with regard to these criteria. Because in MCIC the values of the items on the criteria are typically quantitative, the pairwise comparison is applied in the following, as in Flores et al. (1992), only to evaluate pairwise the importance of criteria by the eigenvalue method. Hence, these values are simply normalised in order to make them commensurable and then combined in a weighted sum for calculating the total scores of each item. In MCIC, ranking techniques are not required because a sorting of items is sufficient. A first attempt to adapt AHP for sorting problems has been presented by Bottani and Rizzi (2008). They use a cluster analysis for grouping items based on their similarities and then applied AHP on the clusters with the aim of reducing the required number of pairwise comparisons. Nevertheless, their approach is improvable in aspects described in the following:

- Let us consider the fictitious example described in De Smet et al. (2012) represented in Figure 1. Four alternatives are evaluated according to two criteria that have to be minimised. The aim is to find a partition of three ordered clusters. The application of a traditional clustering procedure would lead to $\{(\mathrm{a}),(\mathrm{b}),(\mathrm{c}, \mathrm{d})\},\{(\mathrm{a}),(\mathrm{c}),(\mathrm{b}, \mathrm{d})\},\{(\mathrm{a}, \mathrm{b}),(\mathrm{c})$, (d) $\}$ but never to $\{(\mathrm{a}),(\mathrm{c}, \mathrm{b}),(\mathrm{d})\}$, which is the most meaningful ordered partition from a multi-criteria point of view (a being the best alternative, $d$ being dominated by all the other alternatives and (c,b) being intermediate solutions). The application of a clustering technique on the results of AHP rather than on its inputs could provide an ordered clustering. This technique has been implemented in this work. 
Please cite as: . Lolli, A. Ishizaka, R. Gamberini, New AHP-based approaches for multi-criteria inventory classification, International Journal of Production Economics,

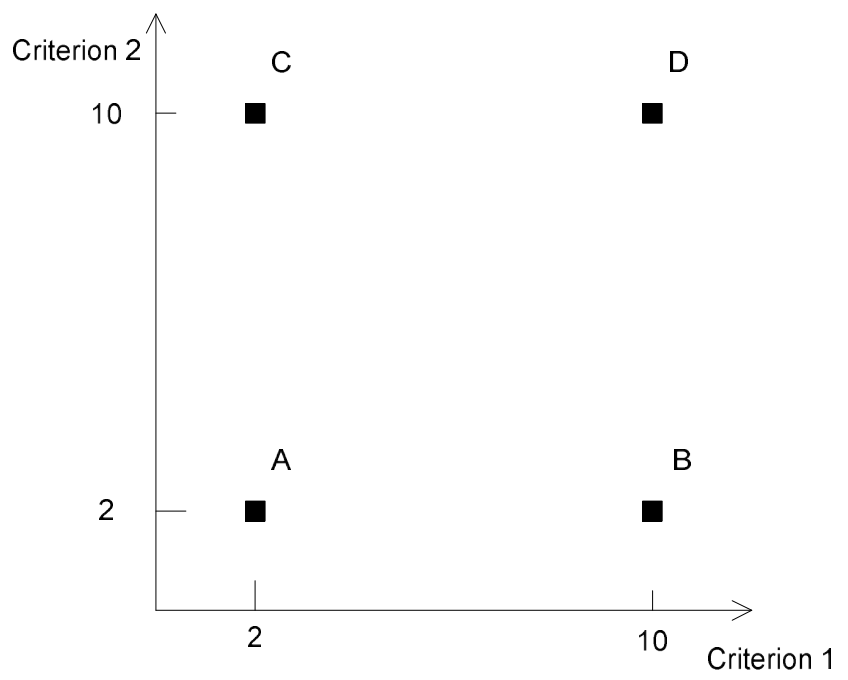

Figure 1: Simple clustering problem (adapted from De Smet et al., 2012)

- The items are allocated to clusters, which do not change for each criterion. This is in contradiction with the principles of multi-criteria decision analysis because an alternative cannot be the best/worst on all criteria.

An alternative attempt to adapt AHP for sorting alternatives into predefined ordered clusters is proposed in AHPSort (Ishizaka et al., 2012). This method requires the definition of limiting or typical central profiles a priori for each class. The a priori definition of profiles by the decision maker may lead to having an item close to other items of another class but far away from the items of the same class. Figure 2 illustrates this situation, which contradicts the aim of MCIC, which is to group similar items into the same compact cluster and well separated from the others. As in the AHP-based approach (section 3.2) and models based on weighted linear optimisation (section 3.3), establishing cardinalities of the clusters a priori leads to a poorly fitting partition of the dataset.

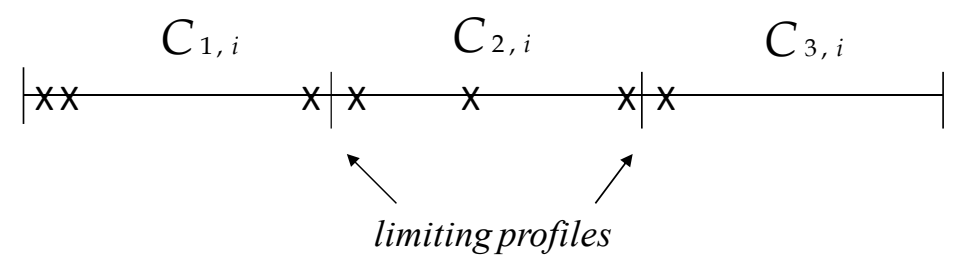

Figure 2. Example of poorly discriminating limiting profiles

To overcome these problems, we have introduced two new variants: AHP-K and AHP-K-Veto, described in the following sections. 
Please cite as: . Lolli, A. Ishizaka, R. Gamberini, New AHP-based approaches for multi-criteria inventory classification, International Journal of Production Economics,

http://dx.doi.org/10.1016/j.ijpe.2014.05.015 (advance online publications)

Other sorting techniques exist but are not considered here because they require parameters from the decision maker that are difficult to evaluate in our case. For example, the UTilités Additives DIScriminantes (UTADIS) (Jacquet-Lagrèze, 1995) requires defining marginal utility functions on each criterion. The construction of these functions is difficult. Several other techniques are issued from the outranking family: ELECTRE-Tri-B (Yu, 1992b; Yu, 1992a; Mousseau and Slowinski, 2000), ELECTRE-Tri-C (Almeida-Dias and al., 2010), FlowSort (Nemery and Lamboray, 2008) and PROMSORT (Araz and Ozkarahan, 2007). These techniques require subjective parameters (indifference and preference thresholds) that may be difficult to elicit.

\subsection{General overview of the methods}

The principal steps of AHP-K and AHP-K-Veto are described in Figure 3.

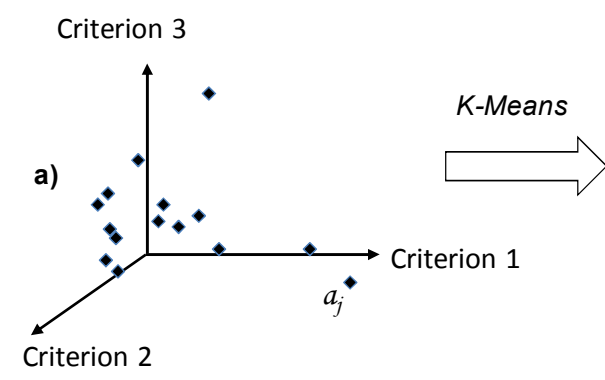

Criterion 1

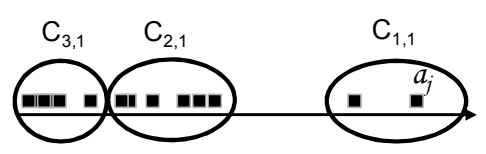

d) Criterion 2

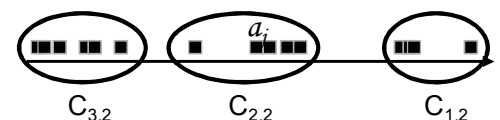

Criterion 3

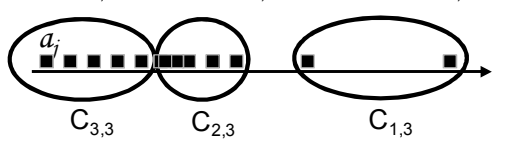

b)
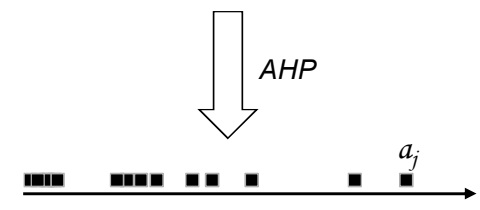

c)

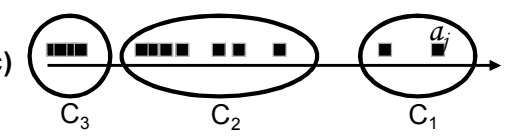

AHP-K

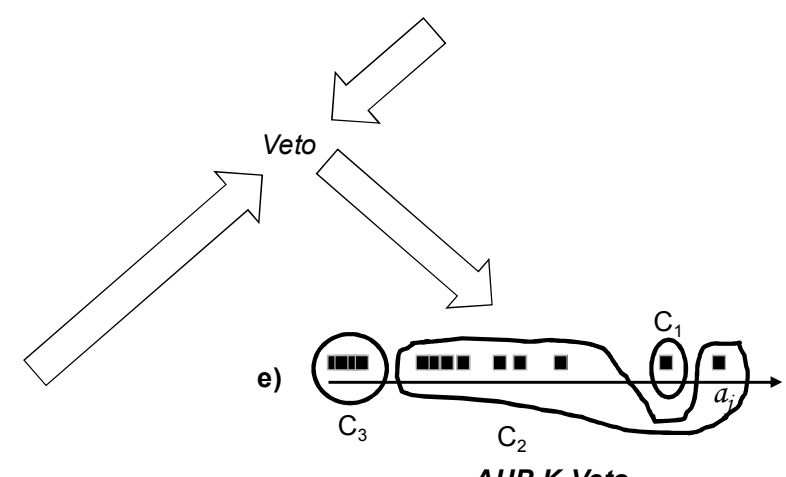

AHP-K-Veto

Figure 3. Principal steps of AHP-K and AHP-K-Veto.

Initially, the standard AHP (Flores et al., 1992) is followed by a suitable clustering algorithm (i.e., K-Means) applied on the final total ranking score (hence, the proposed hybrid approach is called AHP-K in the following). As depicted in Figure 3, given $a_{j}$ items, evaluated in accordance with three criteria (see Figure 3(a)), the adoption of AHP transforms the tri-dimensional problem into a single-sized one (see Figure 3(b)). Subsequently, the K- 
Please cite as: . Lolli, A. Ishizaka, R. Gamberini, New AHP-based approaches for multi-criteria inventory classification, International Journal of Production Economics,

http://dx.doi.org/10.1016/j.ijpe.2014.05.015 (advance online publications)

Means algorithm creates classes $\mathrm{C}_{1}, \mathrm{C}_{2}, \mathrm{C}_{3}$ (or A, B, C, in accordance with the inventory management literature), as shown in Figure 3(c).

However, AHP-K does not allow the decision maker to define a veto on the final results. For example, a $\mathrm{C}_{1}$-classified item (or as usually named in the literature an Aclassified item) might have a very poor score on a particular criterion. Nevertheless, AHP-K does not detect such weakness, because it does not solve a sorting problem on each criterion. Hence, the application of the K-Means algorithm on values $v_{i, j}$ of each item $a_{j}$ on the criterion $i$, per each $i=1, \ldots, I$ could also be applied on each criterion, as described in Figure 3(d). In such a way, the decision maker may now impose a special condition (Veto, as described in Figure 3(e)), i.e., a $C_{3}$-classified item on one or more criterion cannot be $C_{1^{-}}$classified in the final clustering; this method is called AHP-K-Veto.

AHP-K and AHP-K-Veto are described in detail in sections 4.3 and 4.4, respectively.

\subsection{AHP-K}

As previously mentioned, AHP is used to rank items and not to sort them into classes. A subjective $20 \%-70 \%-10 \%$ rule is then applied to the AHP rankings to sort the items into classes (Flores et al., 1992). Nevertheless, as already underlined in section 3.2, such a clustering procedure could violate the main objective of each clustering method, which is to create compact and well-separated clusters. In order to overcome this problem we use a clustering algorithm. As the number $k$ of clusters is known, we opt for the partitioning KMeans algorithm (Jain, 2010; Madhulata, 2012).

The objective of the K-Means algorithm is to minimise the sum of the squared distances between the centroid of each cluster (i.e., the mean point in the case of Euclidean distance) and the items in the cluster. More specifically, given k initial cluster centroids, it assigns each item to its closest centre and then recomputes new centroids, as the means (or centres of mass) of the assigned points. The process is repeated until the squared error is minimised.

In the following, the AHP-K algorithm is described with respect to the specific aim of MCIC and the notation adopted in the paper. In particular, the clustering criterion is the global score $P_{j}$ calculated by AHP through the following steps:

1. Normalise the value of each item $v_{i, j}$ on each criterion $i$. Each criterion can be either positively related (the benefit criterion), or negatively related (the cost 
Please cite as: . Lolli, A. Ishizaka, R. Gamberini, New AHP-based approaches for multi-criteria inventory classification, International Journal of Production Economics,

http://dx.doi.org/10.1016/j.ijpe.2014.05.015 (advance online publications)

criterion) to the importance of the item. In order to obtain the normalized values $v_{i, j}^{*}$ for criterion $i$, the following rules are respectively applied:

$v_{i, j}^{*}=\frac{v_{i, j}-\min _{j=1, \ldots, J} v_{i, j}}{\max _{j=1, \ldots, J} v_{i, j}-\min _{j=1, \ldots, J} v_{i, j}} \quad \forall i=1, \ldots, I: i$ is a benefit criterion

$v_{i, j}^{*}=\frac{\max _{j=1, \ldots, j} v_{i, j}-v_{i, j}}{\max _{j=1, \ldots, j} v_{i, j}-\min _{j=1, \ldots, j} v_{i, j}} \quad \forall i=1, \ldots, I: i$ is a cost criterion

2. Evaluate pairwise the importance of the criteria in order to derive the weight $w_{i}$ given to the criterion $i, \forall i=1, \ldots, I$, by the eigenvalue method (Saaty, 1980) and calculate the global score $P_{j}$ of each item $a_{j}$ by:

$$
P_{j}=\sum_{i=1}^{I} w_{i} \times v_{i, j}^{*} \quad \forall j=1, \ldots, J
$$

3. Let $\bar{P}_{J}$ be the array of $P_{j}$, with $j=1, \ldots, J$. Apply the K-Means algorithm on $\bar{P}_{J}$ Step 3 is clarified in the following,

Suppose that all the items have to be clustered into a set of $\mathrm{N}$ clusters (i.e., classes) with respect to $P_{j}$. The K-Means algorithm finds a partition of $\bar{P}_{J}$, such that the sum of the squared distance between each centroid of a cluster and the item $a_{j}$ in the cluster is minimised. Let $\mu_{\hat{n}}$ be the centroid of the cluster $C_{\widehat{n}}$, where $\hat{n}$ is a generic cluster between 0 and $\mathrm{N}$. The squared distance between $\mu_{\widehat{n}}$ and the items into the cluster $\mathrm{C}_{\widehat{\mathrm{n}}}$ is defined as:

$S D\left(C_{\hat{n}}\right)=\sum_{P_{j} \in C_{\hat{n}}}\left\|P_{j}-\mu_{\hat{n}}\right\|^{2}$

The goal of the K-Means algorithm is to minimise the sum of the squared distances for all $N$ clusters:

$$
S D\left(\bar{P}_{J}\right)=\sum_{n=1}^{N} \sum_{P_{j} \in C_{n}}\left\|P_{j}-\mu_{n}\right\|^{2}
$$

Minimising this objective function is known to be an NP-hard problem (Drineas et al., 1999). The K-Means is a greedy algorithm that converges to a local minimum starting with 
Please cite as: . Lolli, A. Ishizaka, R. Gamberini, New AHP-based approaches for multi-criteria inventory classification, International Journal of Production Economics,

http://dx.doi.org/10.1016/j.ijpe.2014.05.015 (advance online publications)

an initial partition of $N$ clusters and then assigning the values belonging to $\bar{P}_{J}$ to clusters, in order to reduce the $S D\left(\bar{P}_{J}\right)$.

In MCIC, the number of classes is usually predefined hence the output of the KMeans algorithm is a partition of $\bar{P}_{J}$ in classes $C_{A}, C_{B}, C_{C}$ or simply, in accordance with the inventory management literature, $\mathrm{A}, \mathrm{B}$ and $\mathrm{C}$.

\subsection{AHP-K-Veto}

AHP belongs to the family of the full compensatory methods (Ishizaka and Nemery, 2013): a low score can be totally masked by a high score on another criterion. AHP-K inherits of this feature. For example, a C-classified item on a key criterion can belong to the global cluster A. To avoid this hidden weakness, it is necessary to study the items on each single criterion and to provide a definition of each class $C_{n, i}$ (usually 3 in MCIC and named A, B and C) on each criterion $i$ is needed. This can be provided either with N-1 limiting profiles $l p_{n, i}$, which indicate the minimum performance needed on the item $a_{j}$ to belong to the class $C_{n, i}$ or with $\mathrm{N}$ central profiles $c p_{n, i}$, which are given by a typical example of an item $a_{j}$ belonging to the class $C_{n, i}$. Note that $l p_{N, i}=0(\forall i=1, \ldots, I)$ because it is the lowest possible value. Figure 4(a and b) explains these concepts graphically. However, the limiting or central profiles are not always easy to define, for example, when there is no historic data. In this case, the K-Means algorithm can be applied to define the limiting profiles, as described in Figure 3(d). The K-Means algorithm will build compact and well-separated clusters on each single criterion. Subsequently, a veto rule imposed by the decision maker can be inserted in the classification approach. This new integrated method is called AHP-K-Veto.

In AHP-K-Veto, steps 1, 2 and 3 coincide with those reported in the description of AHP-K (section 4.3); hence, they are not repeated in the following. The description continues below with step 4.

4. Apply the K-Means algorithm on each criterion. Equations 8 and 9 become, respectively:

$$
\begin{aligned}
& S D\left(C_{\hat{n}, \hat{\imath}}\right)=\sum_{v_{\hat{\imath}, j}{ }^{*} \in C_{\hat{n}, \hat{\imath}}}\left\|v_{\hat{\imath}, j}{ }^{*}-\mu_{\hat{n}, \hat{\imath}}\right\|^{2} \\
& S D\left(v_{\hat{\imath}, j}{ }^{*}\right)=\sum_{n=1}^{N} \sum_{v_{\hat{\imath}, j}{ }^{*} \in C_{n, \hat{\imath}}}\left\|v_{\hat{\imath}, j}{ }^{*}-\mu_{n, \hat{\imath}}\right\|^{2}
\end{aligned}
$$


Please cite as: . Lolli, A. Ishizaka, R. Gamberini, New AHP-based approaches for multi-criteria inventory classification, International Journal of Production Economics,

http://dx.doi.org/10.1016/j.ijpe.2014.05.015 (advance online publications)

where $v_{\hat{\imath}, j}{ }^{*}$ is the vector of the normalised values of item $a_{j}$ on the criterion $\hat{\imath}$, with $j=1, \ldots, J$, and $\mu_{\hat{n}, \hat{\imath}}$ is the centroid of the cluster $\mathrm{C}_{\widehat{\mathrm{n}}, \hat{\imath}}$. In synthesis, the $\mathrm{K}$ Means implementation on each single criterion leads to $\mathrm{N}$ different clusters for each criterion.

5. A veto rule can now be introduced, i.e., an item that belongs to the highest (lowest) class $C_{n, \hat{\imath}}$ on at least one criterion $\hat{\imath}$ is denied entry into the highest (lowest) aggregated class $C_{N}\left(C_{1}\right)$, regardless of the weight $w_{\hat{\imath}}$ given to the criterion $\hat{\imath}$. In this case, such an item is reassigned into the next aggregated cluster $C_{N-1}\left(C_{2}\right)$. In an ABC-based MCIC, the veto generally implies a higher number of items assigned into the middle cluster B.

(a)

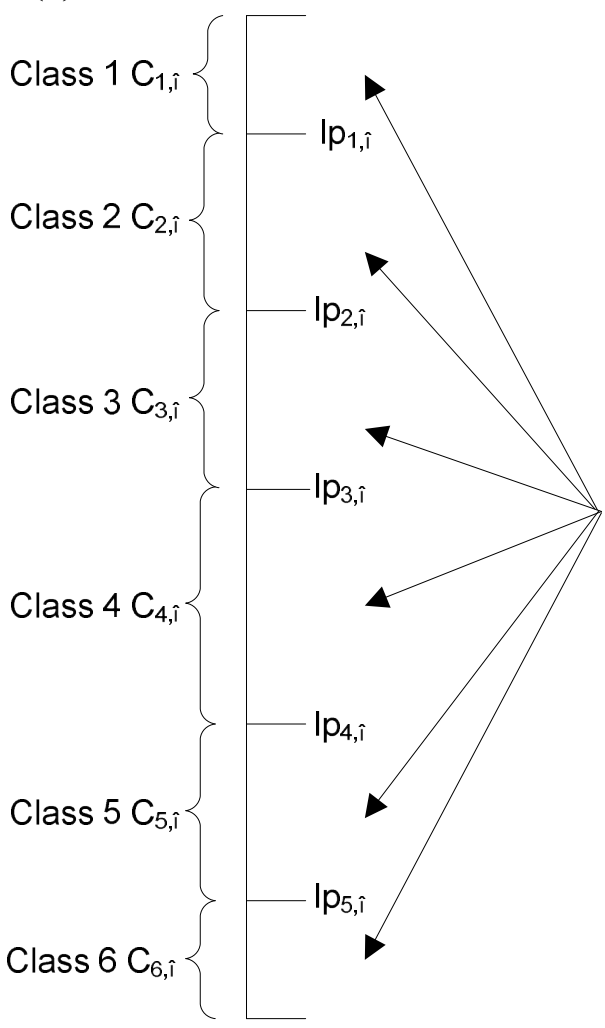

(b)

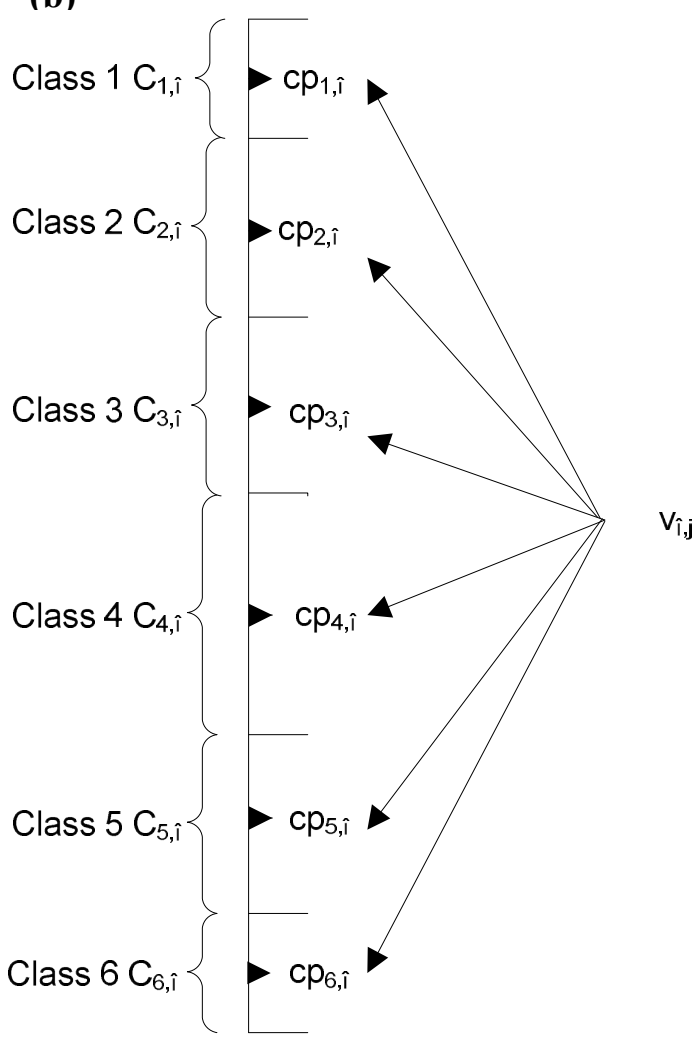

Figure 4. Limiting profiles (a) and central profiles (b) for a generic criterion î.

\section{Case study}

A real-life case study has been carried out in an engineering firm that manufactures electrical resistors on a mass scale. A periodic review system is employed for ninety-five 
Please cite as: . Lolli, A. Ishizaka, R. Gamberini, New AHP-based approaches for multi-criteria inventory classification, International Journal of Production Economics,

http://dx.doi.org/10.1016/j.ijpe.2014.05.015 (advance online publications)

Stock Keeping Units (SKUs) purchased by external suppliers $(\mathrm{J}=95)$. In particular, the inventory position is reviewed weekly for all the SKUs and orders to reach the order-up-to levels of the SKUs are issued at the review instants.

The logistics department is interested in sorting these SKUs into three classes: $C_{A}, C_{B}$ and $C_{C},(\mathrm{~N}=3)$, and to associate all SKUs of the same class to the same target service level for their safety stocks calculation. The target service level is fixed at $99 \%, 95 \%$ and $90 \%$ for the SKUs respectively belonging to the classes $C_{A}, C_{B}$ and $C_{C}$.

In accordance with the management opinion, the SKUs classification should be driven by three criteria $(I=3)$ affecting the target service level. As already underlined in Section 1 , it is worth stressing that the selected criteria needs be selected coherently with the aim of MCIC. In our case, the management has chosen the following criteria for assigning the SKUs to the predefined target service levels:

- Annual Dollar Usage $(A D U) . A D U$ is given by the product of the unitary purchasing cost and the annual demand. The higher the consumption of an SKU is, the higher is the service level associated to it. Thereby, $A D U$ is positively related to the service level of the SKUs, i.e. it is a benefit criterion.

- Critical Factor $(C F)$. As the SKUs are used in different assembly stages, a stock-out of an SKU may lead to more or less serious consequences. For instance, a stock-out of an SKU used in the first assembly stage leads to delays in all the downstream stages. Thereby, $C F$ is assigned according with the technological assembly stage. As in Flores et al. (1992), $C F$ is a non-continuous categorical data. In accordance with the management opinion, it assumes three values: 1 for very critical SKUs; 0.5 for moderately critical SKUs; 0.1 for non-critical SKUs. The higher the $C F$ of an SKU is, the higher its service level should be. Thereby, $C F$ is positively related to the service level.

- The Replenishment Lead Time (LT). A stock-out of an SKU with a high $L T$ will be refilled after a higher time period than a SKU having a low $L T$. Thereby, the higher the $L T$ of an SKU is, the higher the service level is needed. $L T$ is therefore positively related to the service level. In this case, $L T$ ranges from 1 to 7 weeks.

Other criteria could be related with the target service level, for instance the unitary purchasing cost affecting the holding costs. However, the management decided to neglect this 
Please cite as: . Lolli, A. Ishizaka, R. Gamberini, New AHP-based approaches for multi-criteria inventory classification, International Journal of Production Economics,

http://dx.doi.org/10.1016/j.ijpe.2014.05.015 (advance online publications)

criterion because the costs are very similar among all SKUs. In other words, the unitary cost is not a discriminating criterion.

In accordance with MCIC, the three classes of $C_{A}, C_{B}$ and $C_{C}$ are relabeled here as A, $\mathrm{B}$ and C. Furthermore, the local classes on each criterion $i$ are denoted by $A_{i}, B_{i}$ and $C_{i}$, with $i \in\{A D U, C F, L T\}$.

The management selected the AHP-K-Veto (section 4.4) as the most suitable sorting approach due to its ability to overcome the weaknesses of full compensatory methods including AHP and AHP-K as well (section 4.3).

\subsection{Classification with AHP-K-Veto}

The five steps described in section 4.3 and 4.4 are subsequently applied:

\section{Step 1:}

Given the dataset of 95 SKUs, the values on the three criteria of each SKU have to be normalised. In particular, Equation 5 is used for all the criteria, i.e. $A D U, C F$ and $L T$ (benefit criteria) respectively providing $v_{A D U, j}{ }^{*}, v_{C F, j}{ }^{*}$ and $v_{L T, j}{ }^{*}$ (Table 2, column 2, 4 and 6).

\section{Step 2:}

The purchasing manager is asked for evaluating pairwise the importance of the criteria $A D U, C F, L T$. Their weight are derived with the eigenvalue method and and are: $w_{A D U}=0.558, w_{C F}=0.320$ and $w_{L T}=0.122$. The normalised criteria scores of step 1 are then multiplied by these weights to give the global score (Table 2, column 8)

\section{Step 3:}

The K-Means algorithm is applied with the software Orange ${ }^{\circledR}$ on the AHP global scores calculated in the previous step. Because the final solution depends on the initial centroid of the three classes, the K-Means algorithm is restarted 100 times (i.e., the maximum number of times allowed by the software) with initial randomly selected centroids each time. The software selects the solution that minimises Equation 9. Such procedure is repeated four times, i.e., $4 \times 100$ restarts, in order to verify that the best solution is stable. In other words, the selected solution is very likely to be the best achievable one. The values of the three centroids obtained by the K-Means algorithm are: $\mu_{A}=0.878 ; \mu_{B}=0.684 ; \mu_{C}=0.256$. Based on these thresholds and the SKU global score, each SKU is assigned to class A, B or C. 
Please cite as: . Lolli, A. Ishizaka, R. Gamberini, New AHP-based approaches for multi-criteria inventory classification, International Journal of Production Economics,

http://dx.doi.org/10.1016/j.ijpe.2014.05.015 (advance online publications)

\section{Step 4:}

The K-Means algorithm is run also on each single criterion. Specifically, 9 central profiles are defined ( 3 thresholds $\times 3$ criteria) by the centroids of the clusters obtained by the $\mathrm{K}-\mathrm{Means}$ algorithm on each criterion $i$. However, it is note that the application of K-Means on $C F$ is not necessary because it admits a number of possible values $(1,0.5$ and 0.1$)$ equal to the number of classes, i.e. three. Thus, SKUs with $C F$ equal to 1 are A-classified, SKUs with $C F$ equal to 0.5 are B-classified and SKUs with $C F$ equal to 0.1 are C-classified.

As already underlined in the previous step, the final solution of the K-Means algorithm depends on the initialisation. Therefore, a multi-start is also used here. In Table 1, the calculated centroids on $A D U$ and $L T$ are reported, with $C F$ omitted for the aforementioned reasons.

\begin{tabular}{c|c|c} 
& $A D U$ & $L T$ \\
\hline$A_{i}$ & 0.955 & 0.846 \\
\hline$B_{i}$ & 0.592 & 0.464 \\
\hline$C_{i}$ & 0.189 & 0.127
\end{tabular}

Table 1. The centroids of the classes $A_{i}, B_{i}$ and $C_{i}$ achieved by the application of the K-Means algorithm on the criteria $A D U$ and $L T$.

\section{Step 5:}

With the clustering results obtained by applying the K-Means on the AHP global scores (Step 3) and by applying the K-Means on each criterion (Step 4), a veto can be defined. SKUs with at least one criterion classified in class A, cannot be classified in the global class C. Identically, SKUs with at least one criterion classified in class C, cannot be classified in the global class A. The clustering achieved by AHP-K-Veto is reported in the right-hand side of Table 2, along with those obtained by AHP-K. Moreover, the highlighted letters in the first column from the right-hand side of Table 2 indicate the differences between AHP-K and AHP-K-Veto. Ten SKUs (9.5\%) change their classes. In particular, SKUs $\mathrm{s}_{1}, \mathrm{~s}_{8}$ and $\mathrm{s}_{10}$ are classified in the class $\mathrm{C}$ with AHP-K but on the criterion $L T$ they belong to the class A. It is therefore wiser not to place them in the worst class $\mathrm{C}$ but to move them up in the class B. On the contrary, SKUs $\mathrm{s}_{41}, \mathrm{~s}_{56}, \mathrm{~s}_{65}, \mathrm{~s}_{69}, \mathrm{~s}_{71}, \mathrm{~s}_{76}$ and $\mathrm{s}_{81}$ are declassified from the class A to the class B because they belong on class $\mathrm{C}$ on the criterion $L T$. 
Please cite as: . Lolli, A. Ishizaka, R. Gamberini, New AHP-based approaches for multi-criteria inventory classification, International Journal of Production Economics,

http://dx.doi.org/10.1016/j.ijpe.2014.05.015 (advance online publications)

\begin{tabular}{|c|c|c|c|c|c|c|c|c|c|}
\hline Item & $v_{A D U, j}{ }^{*}$ & $C_{A D U}$ & $v_{C F, j}^{*}$ & $C_{C F}$ & $v_{L T, j}{ }^{*}$ & $C_{L T}$ & Score & $\begin{array}{l}\text { Clustering } \\
\text { AHP-K }\end{array}$ & $\begin{array}{l}\text { Clustering } \\
\text { AHP-K-Veto }\end{array}$ \\
\hline s1 & 0.113 & C & 0.1 & C & 0.833 & A & 0.197 & C & B \\
\hline s2 & 0.926 & A & 0.5 & B & 0.167 & $\mathrm{C}$ & 0.697 & B & B \\
\hline s3 & 0.653 & B & 0.5 & B & 0.000 & C & 0.525 & B & B \\
\hline s4 & 0.000 & $\mathrm{C}$ & 0.5 & B & 0.500 & B & 0.221 & $\mathrm{C}$ & $\mathrm{C}$ \\
\hline s5 & 0.920 & A & 0.1 & $\mathrm{C}$ & 0.667 & A & 0.627 & B & B \\
\hline s6 & 0.960 & A & 0.1 & C & 0.000 & $\mathrm{C}$ & 0.568 & B & B \\
\hline s7 & 0.335 & $\mathrm{C}$ & 0.1 & $\mathrm{C}$ & 0.000 & $\mathrm{C}$ & 0.219 & $\mathrm{C}$ & $\mathrm{C}$ \\
\hline s8 & 0.297 & C & 0.1 & C & 0.833 & A & 0.300 & $\mathrm{C}$ & B \\
\hline s9 & 0.951 & A & 0.1 & C & 1.000 & A & 0.684 & B & B \\
\hline $\mathrm{s} 10$ & 0.132 & C & 0.1 & C & 0.833 & A & 0.207 & C & B \\
\hline s11 & 0.914 & A & 0.1 & $\mathrm{C}$ & 0.500 & B & 0.603 & B & B \\
\hline s12 & 0.911 & A & 0.1 & $\mathrm{C}$ & 0.000 & $\mathrm{C}$ & 0.541 & B & B \\
\hline s13 & 0.976 & A & 0.1 & $\mathrm{C}$ & 0.167 & C & 0.597 & B & B \\
\hline s14 & 0.823 & A & 0.5 & B & 0.333 & B & 0.660 & B & B \\
\hline s15 & 0.838 & A & 0.1 & $\mathrm{C}$ & 0.500 & B & 0.561 & B & B \\
\hline s16 & 0.863 & A & 0.1 & $\mathrm{C}$ & 0.833 & A & 0.615 & B & B \\
\hline s17 & 0.877 & A & 0.5 & B & 0.500 & B & 0.710 & B & B \\
\hline s18 & 0.878 & A & 0.5 & B & 0.167 & $\mathrm{C}$ & 0.670 & B & B \\
\hline s19 & 0.675 & B & 1 & A & 0.000 & C & 0.697 & B & B \\
\hline $\mathrm{s} 20$ & 0.884 & A & 0.5 & B & 0.500 & B & 0.714 & B & B \\
\hline $\mathrm{s} 21$ & 0.885 & A & 0.5 & B & 0.500 & B & 0.715 & B & B \\
\hline s22 & 0.890 & A & 1 & A & 0.500 & B & 0.878 & A & A \\
\hline $\mathrm{s} 23$ & 0.892 & A & 1 & A & 0.167 & $\mathrm{C}$ & 0.838 & A & A \\
\hline s24 & 0.907 & A & 0.5 & B & 0.167 & C & 0.686 & B & B \\
\hline $\mathrm{s} 25$ & 0.909 & A & 0.1 & $\mathrm{C}$ & 0.000 & $\mathrm{C}$ & 0.539 & B & B \\
\hline s26 & 0.910 & A & 0.1 & C & 0.500 & B & 0.601 & B & B \\
\hline s27 & 0.915 & A & 0.5 & B & 0.167 & C & 0.691 & B & B \\
\hline $\mathrm{s} 28$ & 0.917 & A & 0.1 & $\mathrm{C}$ & 1.000 & A & 0.666 & B & B \\
\hline s29 & 0.918 & A & 0.1 & C & 0.500 & B & 0.605 & B & B \\
\hline $\mathrm{s} 30$ & 0.919 & A & 0.5 & B & 0.500 & B & 0.734 & B & B \\
\hline $\mathrm{s} 31$ & 0.922 & A & 0.1 & C & 0.667 & A & 0.628 & B & B \\
\hline $\mathrm{s} 32$ & 0.924 & A & 0.5 & B & 0.167 & $\mathrm{C}$ & 0.696 & B & B \\
\hline $\mathrm{s} 33$ & 0.940 & A & 0.5 & B & 0.500 & B & 0.745 & B & B \\
\hline s34 & 0.940 & A & 0.5 & B & 0.167 & C & 0.705 & B & B \\
\hline $\mathrm{s} 35$ & 0.941 & A & 0.5 & B & 0.500 & B & 0.746 & B & B \\
\hline s36 & 0.943 & A & 0.5 & B & 0.000 & C & 0.686 & B & B \\
\hline s37 & 0.388 & C & 0.5 & B & 0.167 & C & 0.397 & C & C \\
\hline $\mathrm{s} 38$ & 0.946 & A & 0.5 & B & 0.000 & $\mathrm{C}$ & 0.688 & B & B \\
\hline s39 & 0.947 & A & 0.5 & B & 0.167 & C & 0.709 & B & B \\
\hline s40 & 0.952 & A & 0.5 & B & 0.000 & C & 0.691 & B & B \\
\hline s41 & 0.952 & A & 1 & A & 0.167 & C & 0.871 & A & B \\
\hline $\mathrm{s} 42$ & 0.956 & A & 1 & A & 0.167 & $\mathrm{C}$ & 0.874 & A & A \\
\hline $\mathrm{s} 43$ & 0.958 & A & 0.5 & B & 0.500 & B & 0.755 & B & B \\
\hline s44 & 0.038 & C & 0.5 & B & 0.167 & C & 0.201 & C & C \\
\hline $\mathrm{s} 45$ & 0.963 & A & 0.5 & B & 0.167 & C & 0.718 & B & B \\
\hline s46 & 0.964 & A & 0.5 & B & 0.167 & C & 0.718 & B & B \\
\hline s47 & 0.965 & A & 0.5 & B & 0.167 & C & 0.719 & B & B \\
\hline $\mathrm{s} 48$ & 0.968 & A & 0.5 & B & 0.167 & C & 0.720 & B & B \\
\hline s49 & 0.968 & A & 0.5 & B & 0.167 & C & 0.721 & B & B \\
\hline $\mathrm{s} 50$ & 0.968 & A & 0.5 & B & 0.000 & C & 0.700 & B & B \\
\hline s51 & 0.970 & A & 0.5 & B & 0.167 & C & 0.722 & B & B \\
\hline $\mathrm{s} 52$ & 0.970 & A & 0.1 & $\mathrm{C}$ & 0.500 & B & 0.635 & B & B \\
\hline s53 & 0.971 & A & 0.5 & B & 0.167 & $\mathrm{C}$ & 0.722 & B & B \\
\hline s54 & 0.971 & A & 0.5 & B & 0.167 & C & 0.722 & B & B \\
\hline s55 & 0.972 & A & 0.1 & C & 0.500 & B & 0.635 & B & B \\
\hline s56 & 0.973 & A & 1 & A & 0.167 & C & 0.883 & A & B \\
\hline s57 & 0.973 & A & 0.5 & B & 0.167 & C & 0.723 & B & B \\
\hline s58 & 0.975 & A & 0.5 & B & 0.167 & C & 0.725 & B & B \\
\hline $\mathrm{s} 59$ & 0.976 & A & 0.5 & B & 0.333 & B & 0.745 & B & B \\
\hline s60 & 0.977 & A & 0.5 & B & 0.167 & $\mathrm{C}$ & 0.726 & B & B \\
\hline s61 & 0.979 & A & 0.1 & C & 1.000 & A & 0.700 & B & B \\
\hline s62 & 0.149 & C & 0.5 & B & 0.167 & C & 0.263 & C & C \\
\hline s63 & 0.981 & A & 0.5 & B & 0.167 & $\mathrm{C}$ & 0.728 & B & B \\
\hline s64 & 0.149 & C & 0.5 & B & 0.333 & B & 0.284 & C & C \\
\hline s65 & 0.984 & A & 1 & A & 0.167 & C & 0.889 & A & B \\
\hline s66 & 0.984 & A & 0.5 & B & 0.500 & B & 0.770 & B & B \\
\hline s67 & 0.985 & A & 0.5 & B & 0.167 & C & 0.730 & B & B \\
\hline s68 & 0.987 & A & 0.5 & B & 0.167 & C & 0.731 & B & B \\
\hline s69 & 0.987 & A & 1 & A & 0.167 & C & 0.891 & A & B \\
\hline s70 & 0.988 & A & 0.5 & B & 0.333 & B & 0.752 & B & B \\
\hline s71 & 0.988 & A & 1 & A & 0.167 & C & 0.892 & A & B \\
\hline s72 & 0.989 & A & 0.5 & B & 1.000 & A & 0.834 & B & B \\
\hline s73 & 0.989 & A & 0.5 & B & 0.500 & B & 0.773 & B & B \\
\hline s74 & 0.989 & A & 0.5 & B & 0.500 & B & 0.773 & B & B \\
\hline s75 & 0.990 & A & 1 & A & 0.167 & C & 0.893 & A & A \\
\hline s76 & 0.991 & A & 1 & A & 0.167 & C & 0.893 & A & B \\
\hline s77 & 0.992 & A & 0.5 & B & 0.167 & C & 0.734 & B & B \\
\hline
\end{tabular}


Please cite as: . Lolli, A. Ishizaka, R. Gamberini, New AHP-based approaches for multi-criteria inventory classification, International Journal of Production Economics,

http://dx.doi.org/10.1016/j.ijpe.2014.05.015 (advance online publications)

\begin{tabular}{|c|c|c|c|c|c|c|c|c|c|}
\hline s78 & 0.993 & A & 0.5 & B & 0.000 & C & 0.714 & B & B \\
\hline s79 & 0.993 & A & 0.1 & C & 0.167 & C & 0.606 & B & B \\
\hline s80 & 0.994 & A & 0.5 & B & 0.167 & C & 0.735 & B & B \\
\hline s81 & 0.994 & A & 1 & A & 0.167 & C & 0.895 & A & B \\
\hline s82 & 0.994 & A & 0.1 & C & 0.000 & C & 0.587 & B & B \\
\hline s83 & 0.384 & C & 1 & A & 0.167 & C & 0.555 & B & B \\
\hline s84 & 0.994 & A & 0.5 & B & 0.167 & C & 0.735 & B & B \\
\hline s85 & 0.448 & B & 0.1 & $\mathrm{C}$ & 0.000 & C & 0.282 & C & C \\
\hline s86 & 0.997 & A & 1 & A & 0.333 & B & 0.917 & A & A \\
\hline s87 & 0.997 & A & 0.5 & B & 0.167 & C & 0.737 & B & B \\
\hline s88 & 0.998 & A & 0.5 & B & 0.167 & C & 0.737 & B & B \\
\hline s89 & 0.146 & C & 0.5 & B & 0.000 & C & 0.241 & C & C \\
\hline s90 & 0.999 & A & 0.1 & $\mathrm{C}$ & 0.167 & C & 0.610 & B & B \\
\hline s91 & 0.999 & A & 0.5 & B & 0.667 & A & 0.799 & A & A \\
\hline s92 & 0.136 & C & 0.5 & B & 0.167 & C & 0.256 & C & C \\
\hline s93 & 0.999 & A & 0.5 & B & 0.167 & C & 0.738 & B & B \\
\hline s94 & 1.000 & A & 0.5 & B & 0.667 & A & 0.799 & A & A \\
\hline s95 & 1.000 & A & 1 & A & 1.000 & A & 1.000 & A & A \\
\hline
\end{tabular}

Table 2. Items clustered with AHP-K and AHP-K-Veto.

\subsection{Discussion}

The application of the novel AHP-K-Veto on this real dataset allows highlighting some relevant features of this approach from an operative point of view.

- The K-Means algorithm helps decision-maker to objectively establish the cardinalities of the clusters without requiring any questionable subjective judgment a priori. In this case, the classes $\mathrm{A}, \mathrm{B}$ and $\mathrm{C}$ are respectively composed by 8,78 and 9 SKUs (respectively $8.4 \%, 82.1 \%$ and $9.5 \%$ of 95 SKUs).

- The Veto significantly modifies the AHP-K clustering. In fact, almost $10 \%$ of the SKUs are reclassified in the class B.

- The practical implications of the novel approach are promising because it shows its potential without requiring any specific technical knowledge and expertise. The availability of user-friendly software, both for evaluating the pairwise importance of the criteria and for the application of the K-Means algorithm, supports the decisionmakers. The revised compensatory method as the AHP-K-Veto is easily understandable and intuitive. Furthermore, the application of the K-Means algorithm on each single criterion significantly improves the explicit knowledge on the SKUs.

\section{Comparison of classification methods on the Reid's dataset}

In this section, the AHP-K and AHP-K-Veto methods are applied to the dataset provided by Reid (1987). In particular, the following studies are used for comparison: Flores et al., 1992; Ramanathan, 2006; Ng, 2007; Zhou and Fan, 2007; Hadi-Venchel, 2010; Chen, 2011; Mohammaditabar et al., 2012. Thus, forty-seven items $(J=47)$ need to be sorted into three classes $(N=3)$ according to four criteria $(I=4)$ : 
Please cite as: . Lolli, A. Ishizaka, R. Gamberini, New AHP-based approaches for multi-criteria inventory classification, International Journal of Production Economics,

http://dx.doi.org/10.1016/j.ijpe.2014.05.015 (advance online publications)

- $\quad$ Average Unit Cost $(A U C)$,

- Annual Dollar Usage ( $A D U)$,

- $\quad$ Critical Factor $(C F)$,

- $\quad$ Lead Time $(L T)$.

For a fair comparison with the AHP-based clustering method proposed by Flores et al. (1992), the weights given to the criteria must be the same $\left(w_{A U C}=0.079, w_{A D U}=\right.$ $\left.0.091, w_{C F}=0.420, w_{L T}=0.410\right)$, i.e. Step 2 is skipped.

The critical factor is a non-continuous categorical data as in Flores et al. (1992) for a fair comparison ( 1 for very critical items; 0.50 for moderately critical items; 0.01 for noncritical items). However, it is to be noted that the $C F$ has been omitted in $\mathrm{Ng}$ (2007), Zhou and Fan (2007), Hadi-Venchel (2010) and Chen (2011), because non-continuous values are not suitable for linear optimisation models. This drawback of the DEA-based approaches is also observed in Section 6.2.

Table 3 reports the classification achieved by applying the AHP-K and the AHP-KVeto to the Reid's dataset, where the highlighted letters in the last indicate the differences between AHP-K and AHP-K-Veto. Table 4 shows the classification achieved by the other methods on the same dataset.

\begin{tabular}{|c|c|c|c|c|c|c|c|c|c|c|c|}
\hline Item & $v_{A U C, j}{ }^{*}$ & $C_{A U C}$ & $v_{A D U, j}{ }^{*}$ & $C_{A D U}$ & $v_{C F, j}{ }^{*}$ & $C_{C F}$ & $v_{L T, j}{ }^{*}$ & $C_{L T}$ & Score & $\begin{array}{c}\text { Clustering } \\
\text { AHP-K }\end{array}$ & $\begin{array}{l}\text { Clustering } \\
\text { AHP-K-Veto }\end{array}$ \\
\hline s1 & 0.219 & $\mathrm{C}$ & 1.000 & A & 1.000 & A & 0.167 & $\mathrm{C}$ & 0.597 & B & B \\
\hline s2 & 1.000 & A & 0.971 & A & 1.000 & A & 0.667 & B & 0.861 & A & A \\
\hline s3 & 0.091 & $\mathrm{C}$ & 0.862 & A & 1.000 & A & 0.500 & B & 0.711 & A & B \\
\hline s4 & 0.110 & $\mathrm{C}$ & 0.816 & A & 0.010 & $\mathrm{C}$ & 0.000 & $\mathrm{C}$ & 0.083 & $\mathrm{C}$ & B \\
\hline s5 & 0.258 & $\mathrm{C}$ & 0.594 & B & 0.500 & B & 0.333 & B & 0.419 & B & B \\
\hline s6 & 0.127 & $\mathrm{C}$ & 0.501 & B & 0.500 & B & 0.333 & B & 0.400 & B & B \\
\hline s7 & 0.113 & $\mathrm{C}$ & 0.481 & B & 0.500 & B & 0.333 & B & 0.397 & B & B \\
\hline s8 & 0.243 & $\mathrm{C}$ & 0.450 & B & 0.010 & $\mathrm{C}$ & 0.500 & B & 0.265 & $\mathrm{C}$ & $\mathrm{C}$ \\
\hline s9 & 0.333 & $\mathrm{C}$ & 0.412 & B & 1.000 & A & 0.833 & A & 0.825 & A & B \\
\hline $\mathrm{s} 10$ & 0.758 & B & 0.410 & B & 0.500 & B & 0.500 & B & 0.510 & B & B \\
\hline s11 & 0.000 & $\mathrm{C}$ & 0.181 & $\mathrm{C}$ & 1.000 & A & 0.167 & $\mathrm{C}$ & 0.505 & B & B \\
\hline $\mathrm{s} 12$ & 0.077 & $\mathrm{C}$ & 0.175 & $\mathrm{C}$ & 0.500 & B & 0.667 & B & 0.503 & B & B \\
\hline $\mathrm{s} 13$ & 0.397 & $\mathrm{C}$ & 0.174 & $\mathrm{C}$ & 1.000 & A & 1.000 & A & 0.877 & A & B \\
\hline s14 & 0.514 & B & 0.148 & $\mathrm{C}$ & 0.500 & B & 0.667 & B & 0.535 & B & B \\
\hline $\mathrm{s} 15$ & 0.323 & $\mathrm{C}$ & 0.143 & $\mathrm{C}$ & 1.000 & A & 0.333 & B & 0.595 & B & B \\
\hline s16 & 0.195 & $\mathrm{C}$ & 0.135 & $\mathrm{C}$ & 0.500 & B & 0.333 & B & 0.372 & B & B \\
\hline s17 & 0.047 & $\mathrm{C}$ & 0.117 & $\mathrm{C}$ & 0.500 & B & 0.500 & B & 0.427 & B & B \\
\hline $\mathrm{s} 18$ & 0.217 & $\mathrm{C}$ & 0.098 & $\mathrm{C}$ & 0.500 & B & 0.833 & A & 0.575 & B & B \\
\hline s19 & 0.207 & $\mathrm{C}$ & 0.094 & $\mathrm{C}$ & 0.500 & B & 0.667 & B & 0.506 & B & B \\
\hline s20 & 0.260 & $\mathrm{C}$ & 0.076 & $\mathrm{C}$ & 0.500 & B & 0.500 & B & 0.440 & B & B \\
\hline $\mathrm{s} 21$ & 0.094 & $\mathrm{C}$ & 0.075 & $\mathrm{C}$ & 1.000 & A & 0.500 & B & 0.639 & B & B \\
\hline $\mathrm{s} 22$ & 0.292 & $\mathrm{C}$ & 0.074 & $\mathrm{C}$ & 0.500 & B & 0.500 & B & 0.442 & B & B \\
\hline $\mathrm{s} 23$ & 0.397 & $\mathrm{C}$ & 0.070 & $\mathrm{C}$ & 1.000 & A & 0.500 & B & 0.662 & A & B \\
\hline s24 & 0.137 & $\mathrm{C}$ & 0.064 & $\mathrm{C}$ & 1.000 & A & 0.333 & B & 0.573 & B & B \\
\hline $\mathrm{s} 25$ & 0.156 & $\mathrm{C}$ & 0.059 & $\mathrm{C}$ & 0.010 & $\mathrm{C}$ & 0.000 & $\mathrm{C}$ & 0.018 & $\mathrm{C}$ & $\mathrm{C}$ \\
\hline s26 & 0.140 & $\mathrm{C}$ & 0.054 & $\mathrm{C}$ & 0.010 & $\mathrm{C}$ & 0.333 & B & 0.153 & $\mathrm{C}$ & $\mathrm{C}$ \\
\hline s27 & 0.385 & $\mathrm{C}$ & 0.053 & $\mathrm{C}$ & 0.010 & $\mathrm{C}$ & 0.000 & $\mathrm{C}$ & 0.035 & $\mathrm{C}$ & $\mathrm{C}$ \\
\hline $\mathrm{s} 28$ & 0.358 & $\mathrm{C}$ & 0.050 & $\mathrm{C}$ & 0.010 & $\mathrm{C}$ & 0.833 & A & 0.374 & B & B \\
\hline s29 & 0.631 & B & 0.042 & $\mathrm{C}$ & 0.010 & $\mathrm{C}$ & 1.000 & A & 0.463 & B & B \\
\hline s30 & 0.248 & $\mathrm{C}$ & 0.034 & $\mathrm{C}$ & 0.010 & $\mathrm{C}$ & 0.000 & $\mathrm{C}$ & 0.023 & $\mathrm{C}$ & $\mathrm{C}$ \\
\hline s31 & 0.326 & $\mathrm{C}$ & 0.033 & $\mathrm{C}$ & 0.500 & B & 0.667 & B & 0.510 & B & B \\
\hline s32 & 0.234 & $\mathrm{C}$ & 0.032 & $\mathrm{C}$ & 1.000 & A & 0.167 & $\mathrm{C}$ & 0.509 & B & B \\
\hline
\end{tabular}


Please cite as: . Lolli, A. Ishizaka, R. Gamberini, New AHP-based approaches for multi-criteria inventory classification, International Journal of Production Economics,

http://dx.doi.org/10.1016/j.ijpe.2014.05.015 (advance online publications)

\begin{tabular}{|c|c|c|c|c|c|c|c|c|c|c|c|}
\hline s33 & 0.217 & $\mathrm{C}$ & 0.030 & $\mathrm{C}$ & 0.010 & $\mathrm{C}$ & 0.667 & B & 0.293 & $\mathrm{C}$ & $\mathrm{C}$ \\
\hline s34 & 0.010 & $\mathrm{C}$ & 0.028 & $\mathrm{C}$ & 0.010 & $\mathrm{C}$ & 1.000 & A & 0.413 & B & B \\
\hline s35 & 0.271 & $\mathrm{C}$ & 0.027 & $\mathrm{C}$ & 0.010 & $\mathrm{C}$ & 0.333 & B & 0.160 & $\mathrm{C}$ & $\mathrm{C}$ \\
\hline s36 & 0.174 & $\mathrm{C}$ & 0.024 & $\mathrm{C}$ & 1.000 & A & 0.333 & B & 0.572 & B & B \\
\hline s37 & 0.121 & $\mathrm{C}$ & 0.021 & $\mathrm{C}$ & 0.010 & $\mathrm{C}$ & 0.667 & B & 0.285 & $\mathrm{C}$ & $\mathrm{C}$ \\
\hline s38 & 0.304 & $\mathrm{C}$ & 0.019 & $\mathrm{C}$ & 0.500 & B & 0.333 & B & 0.370 & B & B \\
\hline s39 & 0.266 & $\mathrm{C}$ & 0.016 & $\mathrm{C}$ & 0.010 & $\mathrm{C}$ & 0.667 & B & 0.296 & $\mathrm{C}$ & $\mathrm{C}$ \\
\hline s40 & 0.227 & $\mathrm{C}$ & 0.013 & $\mathrm{C}$ & 0.010 & $\mathrm{C}$ & 0.833 & A & 0.361 & B & B \\
\hline s41 & 0.072 & $\mathrm{C}$ & 0.009 & $\mathrm{C}$ & 0.010 & $\mathrm{C}$ & 0.167 & $\mathrm{C}$ & 0.075 & $\mathrm{C}$ & $\mathrm{C}$ \\
\hline s42 & 0.159 & $\mathrm{C}$ & 0.009 & $\mathrm{C}$ & 0.010 & $\mathrm{C}$ & 0.167 & $\mathrm{C}$ & 0.082 & $\mathrm{C}$ & $\mathrm{C}$ \\
\hline s43 & 0.121 & $\mathrm{C}$ & 0.006 & $\mathrm{C}$ & 0.010 & $\mathrm{C}$ & 0.667 & B & 0.283 & $\mathrm{C}$ & $\mathrm{C}$ \\
\hline s44 & 0.211 & $\mathrm{C}$ & 0.004 & $\mathrm{C}$ & 0.010 & $\mathrm{C}$ & 0.333 & B & 0.154 & $\mathrm{C}$ & $\mathrm{C}$ \\
\hline s45 & 0.143 & $\mathrm{C}$ & 0.002 & $\mathrm{C}$ & 0.010 & $\mathrm{C}$ & 1.000 & A & 0.421 & B & B \\
\hline s46 & 0.116 & $\mathrm{C}$ & 0.001 & $\mathrm{C}$ & 0.010 & $\mathrm{C}$ & 0.333 & B & 0.146 & $\mathrm{C}$ & $\mathrm{C}$ \\
\hline s47 & 0.016 & $\mathrm{C}$ & 0.000 & $\mathrm{C}$ & 0.010 & $\mathrm{C}$ & 0.667 & B & 0.275 & $\mathrm{C}$ & $\mathrm{C}$ \\
\hline
\end{tabular}

Table 3. Data source from Reid (1987) and items clustered with AHP-K and AHP-K-Veto.

\begin{tabular}{|c|c|c|c|c|c|c|c|c|c|}
\hline Item & $\begin{array}{c}\text { Flores et } \\
\text { al. (1992) }\end{array}$ & $\begin{array}{c}\text { Ramanthan } \\
\text { (2006) }\end{array}$ & $\begin{array}{c}\mathrm{Ng} \\
(2007)\end{array}$ & $\begin{array}{c}\text { Zhou and Fan } \\
(2007)\end{array}$ & $\begin{array}{c}\text { Hadi-Venchel } \\
(2010)\end{array}$ & $\begin{array}{l}\text { Chen } \\
(2011)\end{array}$ & $\begin{array}{c}\text { Mohammaditabar } \\
\text { et al. (2012) }\end{array}$ & AHP-K & AHP-K-Veto \\
\hline s1 & $\mathrm{A}$ & $\mathrm{B}$ & $\mathrm{A}$ & $\mathrm{A}$ & $\mathrm{A}$ & $\mathrm{A}$ & $\mathrm{A}$ & $\mathrm{B}$ & $\mathrm{B}$ \\
\hline s2 & $\mathrm{A}$ & $\mathrm{C}$ & $\mathrm{A}$ & $\mathrm{A}$ & $\mathrm{A}$ & $\mathrm{A}$ & A & $\mathrm{A}$ & $\mathrm{A}$ \\
\hline s3 & A & $\mathrm{C}$ & A & $\mathrm{A}$ & $\mathrm{A}$ & $\mathrm{A}$ & A & $\mathrm{A}$ & $\mathrm{B}$ \\
\hline s4 & $\mathrm{C}$ & A & A & $\mathrm{C}$ & A & $\mathrm{B}$ & A & $\mathrm{C}$ & $\mathrm{B}$ \\
\hline s5 & $\mathrm{B}$ & $\mathrm{C}$ & A & $\mathrm{B}$ & $\mathrm{A}$ & $\mathrm{B}$ & A & B & $\mathrm{B}$ \\
\hline s6 & $\mathrm{C}$ & $\mathrm{C}$ & A & $\mathrm{C}$ & $\mathrm{B}$ & $\mathrm{B}$ & A & B & $\mathrm{B}$ \\
\hline s7 & $\mathrm{C}$ & $\mathrm{C}$ & $\mathrm{B}$ & $\mathrm{C}$ & B & $\mathrm{B}$ & A & $\mathrm{B}$ & $\mathrm{B}$ \\
\hline s8 & $\mathrm{C}$ & $\mathrm{C}$ & $\mathrm{B}$ & B & $\mathrm{B}$ & $\mathrm{B}$ & A & $\mathrm{C}$ & $\mathrm{C}$ \\
\hline s9 & $\mathrm{A}$ & $\mathrm{C}$ & $\mathrm{A}$ & $\mathrm{A}$ & $\mathrm{A}$ & $\mathrm{A}$ & A & $\mathrm{A}$ & $\mathrm{B}$ \\
\hline s10 & $\mathrm{B}$ & $\mathrm{C}$ & A & A & A & A & A & B & B \\
\hline s11 & B & $\mathrm{C}$ & $\mathrm{C}$ & $\mathrm{C}$ & $\mathrm{C}$ & $\mathrm{C}$ & A & B & B \\
\hline $\mathrm{s} 12$ & B & $\mathrm{C}$ & B & B & B & B & B & B & B \\
\hline s13 & A & $\mathrm{C}$ & A & A & A & A & B & A & B \\
\hline s14 & B & A & B & A & A & B & B & B & B \\
\hline $\mathrm{s} 15$ & A & A & $\mathrm{C}$ & $\mathrm{C}$ & $\mathrm{C}$ & $\mathrm{C}$ & B & B & B \\
\hline s16 & $\mathrm{C}$ & A & $\mathrm{C}$ & $\mathrm{C}$ & $\mathrm{C}$ & $\mathrm{C}$ & B & B & B \\
\hline s17 & B & B & $\mathrm{C}$ & $\mathrm{C}$ & $\mathrm{C}$ & $\mathrm{C}$ & B & B & B \\
\hline $\mathrm{s} 18$ & A & A & B & A & B & B & B & B & B \\
\hline s19 & B & A & B & B & B & B & B & B & B \\
\hline $\mathrm{s} 20$ & B & B & $\mathrm{C}$ & B & $\mathrm{C}$ & $\mathrm{C}$ & B & B & B \\
\hline $\mathrm{s} 21$ & A & B & $\mathrm{C}$ & $\mathrm{C}$ & $\mathrm{C}$ & $\mathrm{C}$ & B & B & B \\
\hline $\mathrm{s} 22$ & B & B & $\mathrm{C}$ & B & $\mathrm{C}$ & $\mathrm{C}$ & B & B & B \\
\hline $\mathrm{s} 23$ & A & B & B & B & B & $\mathrm{C}$ & B & A & B \\
\hline s24 & A & $\mathrm{C}$ & $\mathrm{C}$ & $\mathrm{C}$ & $\mathrm{C}$ & $\mathrm{C}$ & B & B & B \\
\hline $\mathrm{s} 25$ & $\mathrm{C}$ & $\mathrm{C}$ & $\mathrm{C}$ & $\mathrm{C}$ & $\mathrm{C}$ & $\mathrm{C}$ & $\mathrm{C}$ & $\mathrm{C}$ & $\mathrm{C}$ \\
\hline $\mathrm{s} 26$ & $\mathrm{C}$ & $\mathrm{C}$ & $\mathrm{C}$ & $\mathrm{C}$ & $\mathrm{C}$ & $\mathrm{C}$ & $\mathrm{C}$ & $\mathrm{C}$ & $\mathrm{C}$ \\
\hline s27 & $\mathrm{C}$ & B & $\mathrm{C}$ & $\mathrm{C}$ & $\mathrm{C}$ & $\mathrm{C}$ & $\mathrm{C}$ & $\mathrm{C}$ & $\mathrm{C}$ \\
\hline s28 & $\mathrm{C}$ & A & B & $\mathrm{A}$ & B & $\mathrm{A}$ & $\mathrm{C}$ & B & B \\
\hline s29 & B & A & A & A & A & A & $\mathrm{C}$ & B & B \\
\hline $\mathrm{s} 30$ & $\mathrm{C}$ & $\mathrm{C}$ & $\mathrm{C}$ & $\mathrm{C}$ & $\mathrm{C}$ & $\mathrm{C}$ & $\mathrm{C}$ & $\mathrm{C}$ & $\mathrm{C}$ \\
\hline $\mathrm{s} 31$ & B & B & B & B & B & B & B & B & B \\
\hline s32 & B & $\mathrm{C}$ & $\mathrm{C}$ & $\mathrm{C}$ & $\mathrm{C}$ & $\mathrm{C}$ & B & B & B \\
\hline $\mathrm{s} 33$ & $\mathrm{C}$ & B & B & B & B & B & $\mathrm{C}$ & $\mathrm{C}$ & $\mathrm{C}$ \\
\hline s34 & $\mathrm{C}$ & A & B & B & B & A & $\mathrm{C}$ & B & B \\
\hline s35 & $\mathrm{C}$ & $\mathrm{C}$ & $\mathrm{C}$ & $\mathrm{C}$ & $\mathrm{C}$ & $\mathrm{C}$ & $\mathrm{C}$ & $\mathrm{C}$ & $\mathrm{C}$ \\
\hline $\mathrm{s} 36$ & B & $\mathrm{C}$ & $\mathrm{C}$ & $\mathrm{C}$ & $\mathrm{C}$ & $\mathrm{C}$ & B & B & B \\
\hline s37 & $\mathrm{C}$ & B & $\mathrm{C}$ & B & $\mathrm{C}$ & B & $\mathrm{C}$ & $\mathrm{C}$ & $\mathrm{C}$ \\
\hline s38 & $\mathrm{C}$ & $\mathrm{C}$ & $\mathrm{C}$ & $\mathrm{C}$ & $\mathrm{C}$ & $\mathrm{C}$ & B & B & B \\
\hline s39 & $\mathrm{C}$ & B & B & B & B & B & $\mathrm{C}$ & $\mathrm{C}$ & $\mathrm{C}$ \\
\hline $\mathrm{s} 40$ & $\mathrm{C}$ & B & B & B & B & B & $\mathrm{C}$ & B & B \\
\hline $\mathrm{s} 41$ & $\mathrm{C}$ & $\mathrm{C}$ & $\mathrm{C}$ & $\mathrm{C}$ & $\mathrm{C}$ & $\mathrm{C}$ & $\mathrm{C}$ & $\mathrm{C}$ & $\mathrm{C}$ \\
\hline $\mathrm{s} 42$ & $\mathrm{C}$ & $\mathrm{C}$ & $\mathrm{C}$ & $\mathrm{C}$ & $\mathrm{C}$ & $\mathrm{C}$ & $\mathrm{C}$ & $\mathrm{C}$ & $\mathrm{C}$ \\
\hline $\mathrm{s} 43$ & $\mathrm{C}$ & B & $\mathrm{C}$ & $\mathrm{C}$ & $\mathrm{C}$ & $\mathrm{C}$ & $\mathrm{C}$ & $\mathrm{C}$ & $\mathrm{C}$ \\
\hline $\mathrm{s} 44$ & $\mathrm{C}$ & $\mathrm{C}$ & $\mathrm{C}$ & $\mathrm{C}$ & $\mathrm{C}$ & $\mathrm{C}$ & $\mathrm{C}$ & $\mathrm{C}$ & $\mathrm{C}$ \\
\hline $\mathrm{s} 45$ & B & A & B & B & B & A & $\mathrm{C}$ & B & B \\
\hline $\mathrm{s} 46$ & $\mathrm{C}$ & $\mathrm{C}$ & $\mathrm{C}$ & $\mathrm{C}$ & $\mathrm{C}$ & $\mathrm{C}$ & $\mathrm{C}$ & $\mathrm{C}$ & $\mathrm{C}$ \\
\hline $\mathrm{s} 47$ & $\mathrm{C}$ & B & $\mathrm{C}$ & $\mathrm{C}$ & $\mathrm{C}$ & $\mathrm{C}$ & $\mathrm{C}$ & $\mathrm{C}$ & $\mathrm{C}$ \\
\hline
\end{tabular}

Table 4. Classification achieved by other approaches. 
Please cite as: . Lolli, A. Ishizaka, R. Gamberini, New AHP-based approaches for multi-criteria inventory classification, International Journal of Production Economics,

http://dx.doi.org/10.1016/j.ijpe.2014.05.015 (advance online publications)

Two different techniques are adopted for the purpose of comparative analyses. The first one (to be discussed in Section 6.1) regards the shape of the classes generated by different methods in terms of compactness and separation. A meaningful clustering validity index is applied for this aim. The second one (to be discussed in Section 6.2) focuses on the percentages of SKUs moving from one class to another or being classified in the same class, by changing the classification method.

\subsection{Clustering validation}

Clustering validation is important in assessing the quality of the obtained solutions (Halkidi et al., 2001). Hence, in our case study, clustering results are tested and compared with the newly proposed $S V$ index (Žalik and Žalik, 2011). It combines two validity criteria: compactness and separation.

The $S V$ index calculation is reported in Equation (12) as the ratio between $S_{N}$ and $V_{N}$ :

$$
S V(N)=\frac{S_{N}}{V_{N}}
$$

where $S_{N}$ is a separation measure, calculated as the sum of pairwise minimal intercluster distances:

$S_{N}=\sum_{n=1}^{N} \min _{m \in[1, \ldots, N], n \neq m} d\left(\mu_{n}, \mu_{m}\right)$

and $V_{N}$ is a measure of compactness. It is the sum of the largest distances between the items of the cluster and their centroid:

$V_{N}=\sum_{n=1}^{N} \max _{a_{j} \in C_{n}} d\left(a_{j}, \mu_{n}\right)$

A high degree of compactness and separation leads to high values of $S V(N)$.

The cluster validity indexes for AHP-K, AHP-K-Veto and the previously proposed methods are reported in Table 5. AHP-K has the highest cluster validity index of 1.04. This is not surprising, as the method is based on the clustering technique K-mean that is developed to group similar items and optimise the separation between classes. We can also remark that the AHP-based approach has a higher clustering validity index than the other approaches. As 
Please cite as: . Lolli, A. Ishizaka, R. Gamberini, New AHP-based approaches for multi-criteria inventory classification, International Journal of Production Economics,

http://dx.doi.org/10.1016/j.ijpe.2014.05.015 (advance online publications)

predictable, the introduction of the veto option in AHP-K-Veto worsens the clustering validity. In fact, it breaches the objective of the clustering methods, which is to generate compact and well-separated clusters. Nevertheless, it permits the detection of hidden problems whilst ensuring a good final cluster validity score: 0.73 , which is comparable with the validity index achieved by Flores et al. (0.72) and beats the results obtained by the DEAbased (Ramanathan, 2006; Ng, 2007; Zhou and Fan, 2007; Hadi-Venchel, 2010; Chen, 2011) and AI-based (Mohammaditabar et al., 2012) approaches.

\begin{tabular}{|c|c|c|}
\hline Author & Method & $\boldsymbol{S} \boldsymbol{V}$ \\
\hline Flores et al. (1992) & AHP-based & 0.72 \\
\hline Ramanathan (2006) & DEA-based & 0.20 \\
\hline Ng (2007) & DEA-based & 0.49 \\
\hline Zhou and Fan (2007) & DEA-based & 0.48 \\
\hline Hadi-Venchel (2010) & DEA-based & 0.49 \\
\hline Chen (2011) & DEA-based & 0.37 \\
\hline Mohammaditabar et al. (2012) & AI & 0.42 \\
\hline \multirow{2}{*}{} & AHP-K & $\mathbf{1 . 0 4}$ \\
\cline { 2 - 3 } & AHP-K-Veto & 0.73 \\
\hline
\end{tabular}

Table 5. The proposed ABC sorting methods and their index validity SV.

\subsection{Comparison among classifications}

This test investigates how AHP-K generates different classes in comparison with the aforementioned methods. In particular, given Table 4, the Table 6 reports the percentages of items reclassified by the AHP-K (e.g. "A $\rightarrow B$ " indicates the percentage of items A-classified by one of the methods in the first column from the left-hand that are B-classified by the AHP$\mathrm{K}$ ), as well as classified in the same classes (e.g. " $\mathrm{A} \rightarrow \mathrm{A}$ ”). 
Please cite as: . Lolli, A. Ishizaka, R. Gamberini, New AHP-based approaches for multi-criteria inventory classification, International Journal of Production Economics,

http://dx.doi.org/10.1016/j.ijpe.2014.05.015 (advance online publications)

\begin{tabular}{|c|c|c|c|c|c|c|c|c|c|c|c|}
\hline Author & $\begin{array}{c}\mathbf{A} \rightarrow \mathbf{A} \\
{[\%]}\end{array}$ & $\begin{array}{c}\mathbf{B} \rightarrow \mathbf{B} \\
{[\%]}\end{array}$ & $\begin{array}{c}\mathbf{C} \rightarrow \mathbf{C} \\
{[\%]}\end{array}$ & $\begin{array}{c}\text { Total } \\
\mathbf{s a m e} \\
\mathbf{c l a s s}\end{array}$ & $\begin{array}{c}\mathbf{A} \rightarrow \mathbf{B} \\
{[\%]}\end{array}$ & $\begin{array}{c}\mathbf{B} \rightarrow \mathbf{A} \\
{[\%]}\end{array}$ & $\begin{array}{c}\mathbf{A} \rightarrow \mathbf{C} \\
{[\%]}\end{array}$ & $\begin{array}{c}\mathbf{C} \rightarrow \mathbf{A} \\
{[\%]}\end{array}$ & $\begin{array}{c}\mathbf{B} \rightarrow \mathbf{C} \\
{[\%]}\end{array}$ & $\begin{array}{c}\mathbf{C} \rightarrow \mathbf{B} \\
{[\%]}\end{array}$ & $\begin{array}{c}\text { Total } \\
\mathbf{c h a n g e}\end{array}$ \\
\hline $\begin{array}{c}\text { Flores et al. } \\
(1992)\end{array}$ & 10.6 & 29.8 & 34.0 & 74.4 & 10.6 & 0.0 & 0.0 & 0.0 & 0.0 & 14.9 & 25.5 \\
\hline $\begin{array}{c}\text { Ramanathan } \\
(2006)\end{array}$ & 0.0 & 14.9 & 19.1 & 34 & 19.1 & 2.1 & 2.1 & 8.5 & 12.8 & 21.3 & 65.9 \\
\hline $\begin{array}{c}\text { Ng (2007) } \\
\text { Zhou and Fan } \\
(2007)\end{array}$ & 8.5 & 21.3 & 25.5 & 55.3 & 10.6 & 2.1 & 2.1 & 0.0 & 6.4 & 23.4 & 44.6 \\
\hline $\begin{array}{c}\text { Hadi-Venchel } \\
(2010)\end{array}$ & 8.5 & 21.3 & 25.5 & 55.3 & 10.6 & 2.1 & 2.1 & 0.0 & 6.4 & 23.4 & 44.6 \\
\hline $\begin{array}{c}\text { Chen (2011) } \\
\text { (20.1 }\end{array}$ & 8.5 & 19.1 & 23.4 & 51 & 12.8 & 0.0 & 0.0 & 2.1 & 10.6 & 23.4 & 48.9 \\
\hline $\begin{array}{c}\text { Mohammaditabar } \\
\text { et al. (2012) }\end{array}$ & 6.4 & 31.9 & 29.8 & 68.1 & 12.8 & 4.3 & 4.3 & 0.0 & 0.0 & 10.6 & 32 \\
\hline
\end{tabular}

Table 6. Percentage of changes between AHP-K and the previous classification methods.

As predictable, the classification of Flores et al. (1992) is the most similar to the AHP-K as they are both AHP-based. However, the application of the K-Means algorithm leads to reclassify $25.5 \%$ of the border items. Whenever constraints on the cardinalities of the classes are not necessary, as it is likely in real industrial situations, the AHP-K and AHP-KVeto reach more rational partitions. However, it is to remark that the addition of a veto worsens the clustering validity (section 6.1) but also permits to bring out any discrepancies between local and global classifications (section 4.4).

The classification of Mohammaditabar et al. (2012) leads to the second highest percentage of items classified into the same classes as AHP-K (68.1\%). In Mohammaditabar et al. (2012), Flores et al. (1992), AHP-K and AHP-K-Veto, the criteria weights are given endogenously. In fact, in our opinion, this approach models well the real inventory classification because the weights are given to the criteria according to their cost structure. Furthermore, weights do not change among the items as in the DEA approaches. In fact, all the DEA-based methods differ substantially from the other approaches. As they want to avoid any subjectivity on the weights assignments, they propose weight linear optimization models where the weights are endogenously achieved per each item. In particular, Table 6 shows that the classifications proposed in Ramanathan (2006), $\mathrm{Ng}$ (2007), Zhou and Fan (2007), Hadi-Venchel (2010) and Chen (2011) do not differ substantially from each other in comparison with that achieved by the AHP-K. However, these approaches may lead to solutions contradicting the cost structure of the items, which in turn should reflect the weights assigned to the criteria in a compensatory perspective, and the final aim of the classification as well. For instance, items 10 is classified $\mathrm{A}$ and 11 is assigned to $\mathrm{C}$ by $\mathrm{Ng}$ (2007), Zhou and 
Please cite as: . Lolli, A. Ishizaka, R. Gamberini, New AHP-based approaches for multi-criteria inventory classification, International Journal of Production Economics,

http://dx.doi.org/10.1016/j.ijpe.2014.05.015 (advance online publications)

Fan (2007), Hadi-Venchel (2010) and Chen (2011), despite their AHP scores being almost equal ( 0.510 and 0.505$)$. This example illustrates the opposite manners of interpreting the relative importance of the items.

Another important limitation of $\mathrm{Ng}$ (2007), Zhou and Fan (2007), Hadi-Venchel (2010) and Chen (2011) is that non-continuous categorical data cannot be taken into account as critical factor. This implies that the resulting models are less accurate due to this missing information. This loss of information may generate irrational classifications. For example, items 24 and 32 in Table 4 are C-classified by all the DEA-based approaches despite their critical factors being 1 . If the aim of the classification is to associate each class to a target cycle service level, as in the presented case study (Section 5), the lowest value of the service level would be irrationality associated to very critical items despite the fact that the weight for the critical factor $\left(w_{c f}=0.420\right)$ is the highest one.

\section{Conclusions}

When the number of inventory items is large, their internal management (e.g., supply, handling and storage) becomes difficult. Therefore, to achieve effective management, their grouping for simplifying the process is often necessary. The management becomes efficient if items in the same group have the same characteristics. It is therefore clear that the traditional $\mathrm{ABC}$ analysis, based only on the criterion usage value, may be effective but not necessarily efficient. Indeed, the whole criticality of an item can only be captured with Multi-Criteria Inventory Control (MCIC) approaches.

In this paper, two new hybrid MCIC methods, based on the K-Means algorithm and AHP have been proposed: AHP-K and AHP-K-Veto. AHP-K uses the K-means algorithm on the global priorities of AHP. In comparison with previously proposed MCICs based only on AHP, DEA or AI, the clustering validity index of AHP-K has a higher value of intra-cluster compactness and inter-clusters separation on the benchmarking dataset of Reid (1987). These superior performances are justified because previous methods set a priori the cardinalities of each final class (A, B and C) in respect of the decision maker's subjectivity. AHP-K generates a posteriori classes through the K-Means algorithm, which groups the items by similarities and generates compact and well-separated clusters and therefore, the inventory management of similar items is more efficient. The disadvantage of AHP is its complete aggregation, where a bad score on a single criterion can be completely masked. In order to avoid hidden problems, we have extended the method into AHP-K-Veto. A veto system 
Please cite as: . Lolli, A. Ishizaka, R. Gamberini, New AHP-based approaches for multi-criteria inventory classification, International Journal of Production Economics,

http://dx.doi.org/10.1016/j.ijpe.2014.05.015 (advance online publications)

prevents an item evaluated as high/bad on at least one criterion to be top/bottom ranked in the global aggregation. The drawback of the veto system is that it worsens the clustering validity index because it contradicts the objective of the clustering methods. It is therefore important to choose a veto with caution and not to abuse of it.

This paper has presented hybrid methods including AHP and K-means. They merge the strengths of a multi-criteria and a clustering technique. One stand-alone off-the-shelf method has limitations due to its inherent assumptions and therefore, is inadequate to provide an effective and realistic analysis. To overcome the limitations of single methods, we expect in future an expansion of hybrid methods in several fields.

\section{ACKNOWLEDGEMENTS}

We wish to thank Kimberley Parry and Sajid Siraj for the proofreading.

\section{References}

Almeida-Dias, J., Figueira, J., Roy, B., 2010. ELECTRE TRI-C: A multiple criteria sorting method based on characteristic. European Journal of Operational Research 204(3), 565 580.

Angulo-Meza, L., Lins, M. P. E., 2002. Review of methods for increasing discrimination in data envelopment analysis. Annals of Operations Research 116(1-4), 225-242.

Araz, C., Ozkarahan, I., 2007. Supplier evaluation and management system for strategic sourcing based on a new multi-criteria sorting procedure. International Journal of Production Economics 106(2), 585-606.

Bottani, E., Rizzi, A., 2008. An adapted multi-criteria approach to suppliers and products selection - An application oriented to lead-time reduction. International Journal of Production Economics 111(2), 763-781.

Cakir, O., Canbolat, M. S. , 2008. A web-based decision support system for multi-criteria inventory classification using fuzzy AHP methodology. Expert Systems with Applications 35(3), 1367-1378.

Chen, J. X., 2011. Peer-estimation for multiple criteria ABC inventory classification. Computers \& Operations Research 38(12), 1784-1791.

Chen, Y., Li, K. W., Marc Kilgour, D., Hipel, K. W., 2008. A case-based distance model for multiple criteria ABC analysis. Computers \& Operations Research 35(3), 776-796. 
Please cite as: . Lolli, A. Ishizaka, R. Gamberini, New AHP-based approaches for multi-criteria inventory classification, International Journal of Production Economics,

http://dx.doi.org/10.1016/j.ijpe.2014.05.015 (advance online publications)

Cohen, M. A., Ernst, R., 1988. Multi-item classification and generic inventory stock control policies. Production and Inventory Management Journal 29(3), 6-8.

De Smet, Y., Nemery, P., Selvaraj, R., 2012. An exact algorithm for the multi-criteria ordered clustering problem. Omega 40(6), 861-869.

Dickie, H. F., 1951. ABC inventory analysis shoots for dollars not pennies. Factory Management and Maintenance 109, 92-94.

Drineas, P., Frieze, A., Kannan, R., Vempala, S., Vinay, V., 1999. Clustering large graphs via the singular value decomposition. Machine Learning 56(1-3), 9-33.

Ernst, R., Cohen, M. A., 1986. Operations Related Groups (ORGs): a clustering procedure for production/inventory systems. Decision Sciences Working Paper 86-09-04, The Wharton School, University of Pennsylvania.

Ernst, R., Cohen, M. A., 1990. Operations Related Groups (ORGs): a clustering procedure for production/inventory systems. Journal of Operations Management 9(4), 574-598.

Flores, B. E., Whybark, D. C., 1986. Multiple criteria ABC analysis. International Journal of Operations and production Management 6(3), 38-46.

Flores, B. E., Whybark, D. C., 1987. Implementing multiple criteria ABC analysis. Journal of Operations Management 7(1-2), 79-85.

Flores, B. E., Olson, D. L., Dorai, V. K., 1992. Management of multi-criteria inventory classification. Mathematical and Computer modelling 16(12), 71-82.

Ghiani, G., Laporte, G., Musmanno, R., 2004. Introduction to logistics systems planning and control. New York: John Wiley and Sons.

Guvenir, H. A., Erel, E., 1998. Multi-criteria inventory classification using a genetic algorithm. European Journal of Operational Research 105(1), 29-37.

Hadi-Vencheh, A., 2010. An improvement to multiple criteria ABC inventory classification. European Journal of Operational Research 201(3), 962-965.

Halkidi, M., Batistakis, Y., Vazirgiannis, M., 2001. On clustering validation techniques. Journal of Intelligent Information Systems 17(2-3), 107-145.

Huiskonen, J., 2001. Maintenance spare parts logistics: special characteristics and strategic choices. International Journal of Production Economics 71(1-3), 125-133.

Ishizaka, A., Pearman, C., Nemery, P., 2012. AHPSort: an AHP based method for sorting problems. International Journal of Production Research 50(17), 4767-4784.

Ishizaka, A., Labib, A., 2011. Review of the main developments in the analytic hierarchy process. Expert systems with applications 38(11), 14336-14345. 
Please cite as: . Lolli, A. Ishizaka, R. Gamberini, New AHP-based approaches for multi-criteria inventory classification, International Journal of Production Economics,

http://dx.doi.org/10.1016/j.ijpe.2014.05.015 (advance online publications)

Jacquet-Lagrèze, E., 1995. An application of the uta discriminant model for the evaluation of r\&d projects. In Pardalos, P., Siskos, Y. \& Zopounidis, C. eds. Advances in multicriteria analysis. Dordrecht: Kluwer Academic Publishers, 203-211.

Jain, A. K., 2010. Data clustering: 50 years beyond k-means. Pattern Recognition Letters 31(8), 651-666.

Johnson, L., Montgomery, D., 1974. Operation research in production planning, scheduling and inventory control. New York: John Wiley and Sons.

Madhulatha, T. S., 2012. An overview on clustering methods. IOSR Journal of Engineering 2(4), 719-725.

Manzini, R., Gamberini, R., 2008. Design, management and control of logistic distribution systems. In: Kordic, V. Supply chain: theory and applications. Vienna: I-Tech Education and Publishing.

Mohammaditabar, D., Ghodsypour, S. H., O’Brien, C., 2012. Inventory control system design by integrating inventory classification and policy selection. International Journal of Production Economics 140(2), 655-659.

Mousseau, V., Slowinski, R., 2000. A user-oriented implementation of the electre-tri method integrating preference elicitation support. Computers \& Operations Research 27 (7-8), 757-777.

Nahmias, S., 1997. Production and operation analysis. New York: McGraw-Hill.

Nemery, P., Lamboray, C., 2008. Flowsort: A flow-based sorting method with limiting or central profiles. TOP 16(1), 90-113.

Ng, W. L., 2007. A simple classifier for multiple criteria ABC analysis. European Journal of Operational Research 177(1), 344-353.

Partovi, F. Y., Anandarajan, M., 2002. Classifying inventory using an artificial neural network approach. Computers \& Industrial Engineering 41(4), 389-404.

Partovi, F. Y., Burton, J., 1993. Using the analytic hierarchy process for ABC analysis. International Journal of Operations \& Production Management 13(9), 29-44.

Partovi, F. Y., Hopton, W. E., 1994. The analytic hierarchy as applied to two types of inventory problems. Production and Inventory Management Journal 35(1), 13-19.

Ramanathan, R., 2006. ABC inventory classification with multiple-criteria using weighted linear optimization. Computers \& Operations Research 33(3), 695-700.

Reid, R., 1987. The ABC method in hospital inventory management: a practical approach. Production and Inventory Management 28(4), 67-70. 
Please cite as: . Lolli, A. Ishizaka, R. Gamberini, New AHP-based approaches for multi-criteria inventory classification, International Journal of Production Economics,

http://dx.doi.org/10.1016/j.ijpe.2014.05.015 (advance online publications)

Saaty, T. L., 1980. The Analytic Hierarchy Process. New York: McGraw-Hill.

Vattani, A., 2011. K-means requires exponentially many iterations even in the plane. Discrete Computational Geometry 45(4), 596-616.

Yu, M. C., 2011. Multi-criteria ABC analysis using artificial-intelligence-based classification techniques. Expert Systems with Applications 38(4), 3416-3421.

Yu, W., 1992a. Aide multi-critère à la décision dans le cadre de la problématique du tri:

Concepts, méthodes et applications. (PhD thesis) Université Paris-Dauphine.

Yu, W., 1992b. Electre tri: Aspects methodologiques et manuel d'utilisation.

Žalik, K. R., Žalik, B., 2011. Validity index for clusters of different sizes and densities. Pattern Recognition Letters 32(2), 221-234.

Zhou, P., Fan, L., 2007. A note on multi-criteria ABC inventory classification using weighted linear optimization. European Journal of Operational Research 182(3), 1488-1491. 